\title{
Microbiological, immunological, and histological changes in the gut of Salmonella Enteritidis-challenged rats fed goat cheese containing Lactobacillus rhamnosus EM1107
}

\author{
F. R. L. Rolim, ${ }^{1}$ C. J. B. Oliveira, ${ }^{2,3}$ O. C. de Freitas Neto, ${ }^{4}$ K. M. O. Dos Santos, ${ }^{5}$ G. C. B. Guerra, ${ }^{6}$ \\ R. V. Rodrigues, ${ }^{7}$ P. O. A. de Assis, ${ }^{8}$ D. F. de S. Araújo, ${ }^{9}$ V. A. G. de Carvalho, ${ }^{10}$ M. L. P. Lemos, ${ }^{2}$ \\ N. M. V. da Silva, ${ }^{2}$ J. K. B. Soares, ${ }^{7}$ H. E. M. Garcia, ${ }^{10}$ E. L. de Souza, ${ }^{8}$ F. de A. L. Souza, ${ }^{11}$ \\ M. E. G. de Barros, ${ }^{11}$ M. E. G. de Oliveira, ${ }^{8}$ and R. C. R. E. Queiroga ${ }^{8 *}$ \\ ${ }^{1}$ Post-Graduate Program in Food Science and Technology, Department of Food Engineering, Federal University of Paraíba, 58051-900, \\ João Pessoa, Brazil \\ ${ }^{2}$ Department of Animal Science, Center for Agricultural Sciences, Federal University of Paraíba, 58397-000, Areia, Brazil \\ ${ }^{3}$ Global One Health initiative (GOHi), The Ohio State University, Columbus 43210 \\ ${ }^{4}$ Department of Preventive Veterinary Medicine, Veterinary School, Federal University of Minas Gerais, 31270-901, Belo Horizonte, Brazil \\ ${ }^{5}$ Brazilian Agricultural Research Corporation (EMBRAPA), 23020-470, Rio de Janeiro, Brazil \\ ${ }^{6}$ Department of Biophysics and Pharmacology, Biosciences Center, Federal University of Rio Grande do Norte, 59064-741, Natal, Brazil \\ ${ }^{7}$ Department of Nutrition, Center for Education and Health, Federal University of Campina Grande, 58175-000, Cuité, Brazil \\ ${ }^{8}$ Department of Nutrition, Health Sciences Center, Federal University of Paraíba, 58051-900, João Pessoa, Brazil \\ ${ }^{9}$ Faculty of Health Sciences of Trairi, Federal University of Rio Grande do Norte, 59200-000, Santa Cruz, Brazil \\ ${ }^{10}$ Department of Morphology, Health Sciences Center, Federal University of Paraíba, 58051-900, João Pessoa, Brazil \\ ${ }^{11}$ Department of Animal Morphology and Physiology, Federal Rural University of Pernambuco, 52171-900, Recife, Brazil
}

\section{ABSTRACT}

Cheeses are able to serve as suitable matrices for supplying probiotics to consumers, enabling appropriate conditions for bacteria to survive gastric transit and reach the gut, where they are assumed to promote beneficial processes. The present study aimed to evaluate the microbiological, immunological, and histological changes in the gut of Salmonella Enteritidis-challenged rats fed goat cheese supplemented with the probiotic strain Lactobacillus rhamnosus EM1107. Thirty male albino Wistar rats were randomly distributed into 5 experimental groups with 6 animals each: negative (NC) and positive (PtC) control groups, control goat cheese (CCh), goat cheese added with L. rhamnosus EM1107 (LrCh), and L. rhamnosus EM1107 only (EM1107). All animals, except NC group were challenged with Salmonella Enteritidis $\left(10^{9} \mathrm{cfu}\right.$ in $1 \mathrm{~mL}$ of saline through oral gavage). Microbial composition was assessed with high-throughput $16 \mathrm{~S}$ rRNA sequencing by means of Illumina MiSeq (Illumina, San Diego, CA). Nuclear fac-

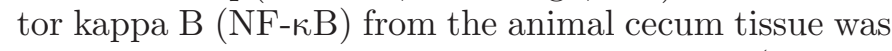
determined by real-time PCR and interleukins (TNF- $\alpha$, IL-1 $\beta$, IL-10, and IFN- $\gamma$ ) by means of ELISA. Myeloperoxidase and malondialdehyde levels were determined

Received May 1, 2020.

Accepted August 1, 2020.

*Corresponding author: rcqueiroga@uol.com.br biochemically. The administration of the L. rhamnosus EM1107 probiotic strain, either as a pure culture or added to a cheese matrix, was able to reduce Salmonella colonization in the intestinal lumen and lessen tissue damage compared with rats from PtC group. In addition, the use of cheese for the probiotic strain delivery ( $\mathrm{LrCh}$ ) was associated with a marked shift in the gut microbiota composition toward the increase of beneficial organisms such as Blautia and Lactobacillus and a reduction in NF- $\kappa \mathrm{B}$ expression. These findings support our hypothesis that cheeses might be explored as functional matrices for the efficacious delivery of probiotic strains to consumers.

Key words: goat cheese, gut microbiome, probiotic, Salmonella Enteritidis, Lactobacillus rhamnosus

\section{INTRODUCTION}

Probiotics are promising alternatives for promoting intestinal health and, consequently, reducing the use of antimicrobial drugs (Ma et al., 2018). Probiotics are defined as living microorganisms that provide benefits to the health of the host when administered in proper concentrations (Hill et al., 2014). These agents have been successfully used for the prevention and treatment of gastrointestinal diseases such as salmonellosis, as previously reported in an in vivo study (Acurcio et al., 2017).

Supplementation with probiotics can promote immunomodulatory effects that are characterized by 
increased innate and adaptive immune functions in response to the modulation of the gut microbiota (Ma et al., 2018). Some Lactobacillus spp. strains play an important role in the regulation of commensal microbiota by inhibiting the growth of opportunistic pathogens, such as Yersinia enterocolitica and Escherichia coli, and promoting the growth of beneficial bacteria (Kamdar et al., 2016; Zhang et al., 2017).

Given the increasing consumption of probiotics, it is necessary to understand the microbial shifts triggered by probiotic foods to elucidate their biological mechanisms on a solid scientific basis (Castillo et al., 2013; Ma et al., 2018). As microbiome plays a key role in many human health conditions (Weinberg et al., 2018), there is an increasing need to better understand the functions of microorganisms in foodstuff, as well as to identify the products derived from their metabolism, going beyond the benefits related to preservation and sensory attributes (Marco et al., 2017). Fermented foods such as cheese are able to serve as suitable matrices for supplying probiotics to consumers, providing appropriate conditions for bacteria to produce enzymes that promote beneficial biochemical processes. These enzymes act in the catabolism of proteins and lipids, supplying specific texture and flavor (Albenzio et al., 2013; Marco et al., 2017) and reducing protein oxidation by the formation of bioactive peptides (Mushtaq et al., 2016).

Coalho cheese is a semi-hard curd cheese commercialized throughout Brazil. This cheese can provide adequate conditions for the protection of probiotic strains during passage through the gastrointestinal tract, as it consists of a solid buffered matrix with high $\mathrm{pH}$ values and low oxygen concentrations (Oliveira et al., 2012; Rolim et al., 2015). Furthermore, probiotic goat cheese needs to be explored as a functional and value-added food (Dantas et al., 2016). Goat dairy products are considered a delicacy in many countries and have been reported to promote anti-inflammatory effects by reducing tissue damage (Rodrigues et al., 2018; Verruck et al., 2019).

Lactobacillus rhamnosus EM1107 is a probiotic strain that has been previously tested in vitro, showing adequate technological properties and survivability rates in food matrices and conditions simulating the gastrointestinal tract (Dos Santos et al., 2015; Rolim et al., 2015). The consumption of cheese with L. rhamnosus EM1107 has been shown to reduce injuries caused by ulcerative colitis in rats, with an overall improvement in immunity and a reduction of inflammation and oxidative stress (Rodrigues et al., 2018). These promising findings encourage further investigation on the putative protective effects of L. rhamnosus EM1107 in animals challenged by enteric pathogens, such as Salmonella enterica, a leading foodborne pathogen worldwide. The mitigation of Salmonella enterica is difficult considering their wide distribution and complex epidemiology, high tolerance and adaptability to different environmental conditions, besides their increasing resistance to multiple antimicrobial drugs (Chen et al., 2013). The present study aimed to evaluate the microbiological, immunological, and histological changes in the gut of rats fed goat cheese supplemented with a probiotic $L$. rhamnosus EM1107 (probiotic cheese) and orally challenged with Salmonella enterica serovar Enteritidis (Salmonella Enteritidis).

\section{MATERIALS AND METHODS}

\section{Bacteria and Inoculum Preparations}

The L. rhamnosus EM1107 strain was provided by the Brazilian Agricultural Research Corporation (EMBRAPA, Rio de Janeiro, Brazil), and the inoculum was prepared according to Rodrigues et al. (2018). The nalidixic acid-resistant Salmonella Enteritidis (SE) P125109 strain used in this study was provided by Paul Barrow, University of Nottingham, UK.

The SE inoculum was prepared on the day before the inoculation and contained $1 \times 10^{9} \mathrm{cfu} / \mathrm{mL}$. Briefly, the strain was streaked onto brilliant green agar (Oxoid, Basingstoke, UK) and incubated at $37^{\circ} \mathrm{C}$ for $24 \mathrm{~h}$. A loopful was transferred to brain-heart infusion (BHI) broth (Sigma-Aldrich, St. Louis, MO) and incubated aerobically at $37^{\circ} \mathrm{C}$ for $18 \mathrm{~h}$. The culture was then centrifuged $\left(4,500 \times g, 15 \mathrm{~min}, 4^{\circ} \mathrm{C}\right)$, washed twice, and resuspended in a sterile saline solution $(\mathrm{NaCl}$ at $0.85 \%$ ). To enumerate the number of viable SE cells in the inoculum, the final bacterial solution was serially diluted $\left(10^{-1}\right.$ to $\left.10^{-9}\right)$, plated onto BHI agar (SigmaAldrich) and incubated under aerobic conditions at $37^{\circ} \mathrm{C}$ for $24 \mathrm{~h}$.

Two types of curd cheese were produced for this study: probiotic cheese, in which coagulation was performed with addition of the coagulant enzyme (rennet) and L. rhamnosus EM1107 $\left(1 \times 10^{9} \mathrm{cfu} / \mathrm{g}\right)$, and cheese without probiotic bacteria (control cheese). Detailed cheese production process is described elsewhere (Rodrigues et al., 2018). The physicochemical properties of the curd cheese used in the present experiment have been reported (Dos Santos et al., 2012). The use of this type of cheese as a matrix enhanced the survivability of the L. rhamnosus EM1107 by improving buffer capacity and nutrient availability and providing more appropriate $\mathrm{pH}$ conditions compared with fermented dairy matrices (Rolim et al., 2015). 


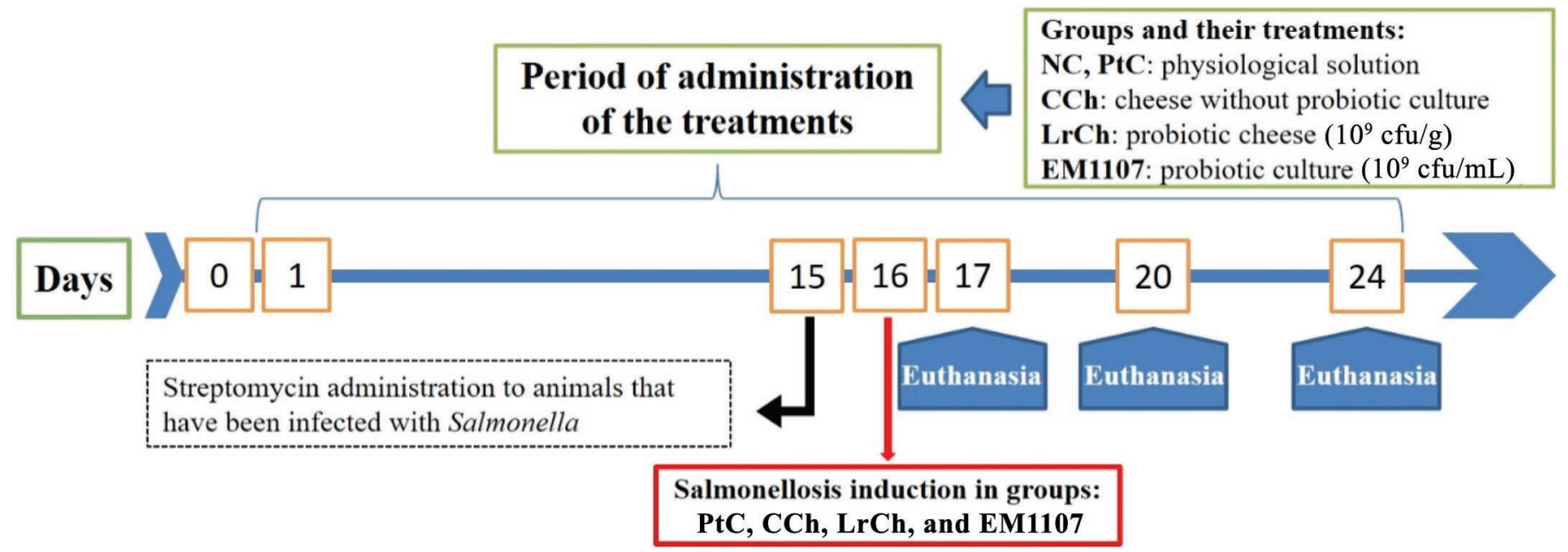

Figure 1. Experimental design showing the treatments performed through chronological order and the main procedures used in the study. $\mathrm{NC}=$ negative control; $\mathrm{PtC}=$ positive control; $\mathrm{CCh}=$ control cheese; LrCh = probiotic cheese; EM1107 = Lactobacillus rhamnosus EM1107.

\section{Animals}

The experimental protocol had been previously approved by the Animal Ethics Committee of the Federal University of Paraíba (CEUA/UFPB-Protocol no. 021/2016), according to regulations established by the National Council for the Control of Animal Experimentation (CONCEA, Brazil). We used male albino Wistar rats (Rattus norvegicus) at 6 weeks of age. They were kept in cages at room temperature $\left( \pm 22^{\circ} \mathrm{C}\right)$, with a 12-h light-dark cycle and ad libitum access to food (Presence-Purina, São Paulo, Brazil) and water.

\section{Experimental Design}

The animals ( $\mathrm{n}=6 /$ group) were randomly distributed into 5 experimental groups. Negative control (NC) and positive control (PtC) animals were given saline solution $(1 \mathrm{~mL})$ as placebo; goat cheese $(1 \mathrm{~g})$ was administered either alone $(\mathbf{C C h})$ or supplemented with L. rhamnosus EM1107 (LrCh); and EM1107 animals were given L. rhamnosus EM1107 only $\left(10^{9} \mathrm{cfu} / \mathrm{mL}\right.$ of saline). Placebo and dietary treatments were administered daily for $24 \mathrm{~d}$ by means of intragastric gavage.

\section{Inoculation and Sampling}

Animals were deprived of water and fed $4 \mathrm{~h}$ before and $2 \mathrm{~h}$ after SE inoculation, as in a previous experimental protocol (Moreau et al., 2016). After this time, the animals had free access to water and food.
All animals, except those in NC treatment, were pretreated with $20 \mathrm{mg}$ streptomycin (Sigma-Aldrich) administered intragastrically on d 15 of the experiment and inoculated with SE $\left(10^{9} \mathrm{cfu}\right) 24 \mathrm{~h}$ later. Thirty minutes before inoculation, SE-inoculated animals were also given $100 \mu \mathrm{L}$ of sodium bicarbonate $(10 \%$ in saline). The NC group animals were given distilled water as pretreatment (Barthel et al., 2003), and saline was given on the day of inoculation (Tennant et al., 2008). The experimental design is presented in Figure 1.

The animals were euthanized at 1, 4, and $8 \mathrm{~d}$ postinfection (DPI; $\mathrm{n}=6$ /group per day). Samples of tissues, feces, and cecal contents were collected for analyses.

\section{Salmonella Enteritidis Counts}

Cecal contents were aseptically collected from the euthanized animals at 1 DPI. Liver and spleen samples were collected at 1,4 , and 8 DPI for bacterial translocation assessment. Samples were serially diluted in sterile saline $(0.85 \% \mathrm{NaCl})$ and aliquots transferred to brilliant green agar (Oxoid) plates supplemented with nalidixic acid (Sigma-Aldrich; $100 \mu \mathrm{g} / \mathrm{mL}$ ), which were incubated under aerobic conditions at $37^{\circ} \mathrm{C}$ for $24 \mathrm{~h}$. Logarithmically transformed $(\log 10)$ SE counts were expressed in colony-forming units per gram (cfu/g). For samples showing no growth in the agar plates, a $1-\mathrm{mL}$ aliquot of the first dilution was transferred to Rappaport Vassiliadis R10 broth (Acumedia, Lansing, MI) and incubated at $37^{\circ} \mathrm{C}$ for $24 \mathrm{~h}$. Afterward, they 
were plated onto brilliant green agar for the qualitative detection of SE.

\section{Microbiota Composition by 16S rRNA Sequencing}

Samples and DNA Extraction. Stool samples from animals were collected at 4 DPI (d 20 of experiment), just before euthanasia. These samples were collected individually, directly transferred to DNase/ RNase free microtubes, and stored at $-80^{\circ} \mathrm{C}$. Genomic DNA was extracted using a commercial kit (DNeasy PowerSoil, Qiagen, Hilden, Germany) according to the manufacturer's recommendations. DNA concentration was determined by means of a micro-volume spectrophotometer (Colibri, Berthold Titertek, Germany), and its integrity assessed visually in 1\% agarose gel.

Library Preparation and Sequencing. The DNA samples were amplified by PCR for the hypervariable regions $\mathrm{V} 3$ and $\mathrm{V} 4$ of the 16s rRNA microbial gene according to a standard protocol (Caporaso et al., 2011). The following primer sequences were used in PCR assays: Fw: 5'-TCGTCGGCAGCGTCAGATGTGTATAAGAGACAGCCTACGGGNGGCWGCAG; Rv: 5'-GTCTCGTGGGCTCGGAGATGTGTATAAGAGACAGGACTACHVGGGTATCTAATC.

The DNA libraries were prepared using the Nextera XT Index Kit (Illumina, San Diego, CA) with multiplex indexing according to the manufacturer's protocol. The PCR products were purified with Agencourt AMPure $\mathrm{XP}$ reagent (Beckman Coulter, Brea, CA) and quantified using a Qubit 3.0 fluorometer (Life Invitrogen, San Diego, CA). Paired-end sequencing was performed in Illumina MiSeq using a $2 \times 250-$ bp cycles V2 kit (Illumina). PhiX (Illumina) kit at 15\% run concentration was used as sequencing control.

16S rRNA Amplicons Preprocessing and Microbiota Analyses. Demultiplexed paired-end fastq sequences were uploaded on QIIME 2 v.19.7 (Bolyen et al., 2019). They were merged, and short reads ( $<200 \mathrm{bp})$ were discarded. The remaining sequences were quality filtered using a minimum PHRED score of 20 and replicated using VSEARCH (Rognes et al., 2016). Chimeric sequences were filtered out using UCHIME (Edgar et al., 2011). Operational taxonomic unit (OTU) identification was performed by means of de novo clusterization method with $99 \%$ similarity between the centroid groups. Sequences were aligned using MAFFT (Katoh et al., 2002) to build the phylogenetic tree by means of Fasttree2 (Price et al., 2010). The number of sequences per sample was normalized to 14,900 reads.

Alpha diversity was estimated by Chao1 and Shannon indices, and $\beta$ diversity was estimated by classical multidimensional scaling using Unweighted Unifrac distance matrix (Lozupone and Knight, 2005), represented in a principal coordinate analysis. Relative OTU abundances were assessed using Phyloseq v.1.8.2 (McMurdie and Holmes, 2013). Taxonomic classification was assigned through the Naïve Bayes method using the reference database SILVA v. 132 cured for V3-V4 regions with 99\% OTU similarities (Quast et al., 2013). The linear discriminant analysis effect size (LEfSe) was performed according to Segata et al. (2011) to detect significant differences between the treatment groups in terms of specific OTU abundances. The LEfSe refers to individual pairwise comparisons between the $\mathrm{NC}$ and the other groups.

\section{Gene Expression by Real-Time PCR}

The expression of nuclear factor kappa B (NF- $\mathbf{k B})$ from the animal cecum tissue was performed by means of real-time PCR analysis according to Rodrigues et al. (2018) using NF- $\kappa \mathrm{B}$ p65 primers (Fw: GAAGAAGCGAGACCTGGAGCAA; Rv: GTTGATGGTGCTGAGGGATGCT). Glyceraldehyde-3-phosphate dehydrogenase was used as the reference gene, amplified by the primers Fw: AACTTGGCATCGTGGAAGG; Rv: GTGGatGCAGGGATGATGATGTTC. Primers were designed using the software Primer express 3.0.1. (Thermo Fisher) and synthetized by Invitrogen Life Technologies (Thermo Fisher Scientific Inc., Waltham, MA).

\section{Biochemical Analyses}

Cecum samples were homogenized in ice-cold 10 mmol/L phosphate buffer $\mathrm{pH} 7.4$ (1:5 wt/vol) and centrifuged at $9,000 \times g$ at $4^{\circ} \mathrm{C}$ for $10 \mathrm{~min}$. The supernatant was used to determine the concentrations of tumor necrosis factor- $\alpha$ (TNF- $\alpha)$, IL-1 $\beta$, IL-10, and IFN- $\gamma$ by enzyme-linked immunosorbent assay (ELISA) using commercial kits (R \& D Systems, Minneapolis, MN), according to the manufacturer's recommendations. Results were expressed in nanograms per gram $(\mathrm{ng} / \mathrm{g})$ of tissue.

Myeloperoxidase (MPO) was determined by the method described by Krawisz et al. (1984) and the results were expressed as units per gram $(\mathrm{U} / \mathrm{g})$ of tissue. Each MPO unit is defined as the amount of the enzyme that catalyzes $1 \mathrm{nmol} / \mathrm{min}$ of hydrogen peroxide at $25^{\circ} \mathrm{C}$. The absorbance was interpolated by means of a standard curve using human leukocyte myeloperoxidase (M6908, Sigma-Aldrich LTDA, São Paulo, Brazil). Malondialdehyde levels (MDA) were determined as described by Esterbauer and Cheeseman (1990), and results were calculated by interpolation in a standard 
curve of malonaldehyde bis (diethyl acetal; T9889, Sigma-Aldrich LTDA) and expressed in nanomoles per gram of tissue. The absorbance was measured in a microplate reader (Polaris, Celer Biotechnology S/A, Belo Horizonte, Minas Gerais, Brazil) at $450 \mathrm{~nm}$ for cytokines and MPO, and at $586 \mathrm{~nm}$ for MDA.

\section{Histopathological Analysis}

Fragments of the cecum were fixed in $10 \%$ formalin for $24 \mathrm{~h}$ and then processed for histological analysis under routine standard procedures. Slides were mounted with 5- $\mu \mathrm{m}$ sections and Entellan (Merck, Kenilworth, NJ) before staining with hematoxylin and eosin.

\section{Statistical Analyses}

Conventional microbiological analyses of cecal contents, biochemical determinations, and gene expression by real-time PCR were expressed as treatment mean \pm standard error. Differences among treatment means were tested by ANOVA, followed by Tukey test at $5 \%$ significance level $(P<0.05)$. Statistical analyses were performed using Graph Pad Prism 5.0 (GraphPad Software Inc., San Diego, CA).

For the microbiota analysis using NGS sequencing, $\alpha$ diversity index differences were evaluated by nonparametric Kruskal-Wallis pairwise test $(P<0.05)$. Beta diversity dissimilarities among treatments were evaluated by permutational multivariate analysis (Anderson, 2001).

\section{RESULTS}

\section{Intestinal Colonization and Systemic Salmonella Infection}

The SE counts were obtained from the cecal contents of all inoculated rats at 1 DPI. No SE was detected in the animals in the uninoculated control group. A significant difference $(P<0.05)$ in mean SE counts was observed across the treatments (Table 1 ). Rats receiving EM1107 or LrCh showed lower SE counts in the

Table 1. Salmonella Enteritidis counts (mean \pm SEM) in the cecal contents of rats $24 \mathrm{~h}$ after the challenge

\begin{tabular}{lc}
\hline Group & Count $^{1}\left(\log _{10} \mathrm{cfu} / \mathrm{g}\right)$ \\
\hline Positive control & $4.93 \pm 0.39^{\mathrm{a}}$ \\
Control cheese & $4.75 \pm 0.28^{\mathrm{a}}$ \\
Probiotic cheese & $4.22 \pm 0.31^{\mathrm{b}}$ \\
Lactobacillus rhamnosus EM1107 & $4.32 \pm 0.23^{\mathrm{b}}$ \\
\hline
\end{tabular}

$\overline{{ }^{a, b} \text { Means in a same column with different letters differ significantly }(P}$ $<0.05)$.

Journal of Dairy Science Vol. 104 No. 1, 2021 cecal contents compared with the $\mathrm{PtC}$ and $\mathrm{CCh}$ groups. Translocation of SE to the liver and spleen of inoculated animals was assessed by microbial culture at 1 , 4, and 8 DPI (data not shown). The presence of SE in the liver and spleen was detected from the beginning of the infection, indicating early penetration through the intestinal barrier and bacterial translocation. However, no statistical difference among the treatment groups was observed.

\section{Microbiota Composition by 16 S rRNA Sequencing}

Reads ranged from 200 to 490 base pairs, averaging 447.13 base pairs. A total of 36,600 different OTU were obtained. Simpson and Shannon's index values were higher $(P<0.05)$ in NC compared with LrCh group, indicating a reduced gut microbial evenness associated with the use of the probiotic cheese. On the other hand, rats from LrCh group showed highest values for microbial richness (Chao1 and ACE plots), probably due to the increase of lactic acid bacteria $(\mathbf{L A B})$ in the gut (Figure 2A and Supplemental Figure S1, https://doi .org/10.3168/jds.2019-18820). According to the beta diversity analysis (Figure 2B), NC and $\mathrm{LrCh}$ were the most dissimilar groups in terms of microbial composition.

Firmicutes and Bacteroidetes were the most abundant phyla across the treatments (Figure 3). Animals fed LrCh had marked increase in Firmicutes (69.82\%) compared with NC (49.43\%). The CCh group was the only group showing higher Bacteroidetes abundance (42.88\%) compared with the control NC (39.82\%), whereas all other groups had lower abundances (PtC $=21.58 \% ; \mathrm{LrCh}=22.54 \%$; EM1107 $=32.15 \%$ ). Spirochaetes were mostly detected in NC group. The microbial abundances related to class and order levels are shown in Supplemental Figures S2 and S3 (https://doi .org/10.3168/jds.2019-18820), respectively.

At the family level (Figure 4), the most marked shifts in the microbiota were observed in rats from $\mathrm{PtC}$ and $\mathrm{LrCh}$ groups compared with NC. Both PtC and LrCh showed increased abundances of Erysipelotrichaceae (8.41 and $7.29 \%$, respectively) compared with NC (1.55\%), CCh (3.4\%), and EM1107 (3.55\%). Higher abundances of Lachnospiraceae were observed in $\mathrm{LrCh}$ (40.36\%), CCh (37.66\%), and EMM1107 (36\%) compared with $\mathrm{PtC}(30.49 \%)$ and $\mathrm{NC}(27.46 \%)$. Prevotellaceae abundances were similar between CCh (37.66\%) and $\mathrm{NC}(36.89 \%)$ groups, which were higher than those observed in EM1107 (26.58\%), LrCh (18.48\%), and PtC (17.21\%). All groups showed reduced Ruminococcaceae abundances compared with NC (23.51\%): PtC (19.38\%), EM1107 (16.98\%), LrCh (16.09\%), and CCh $(14.92 \%)$. 
(A)
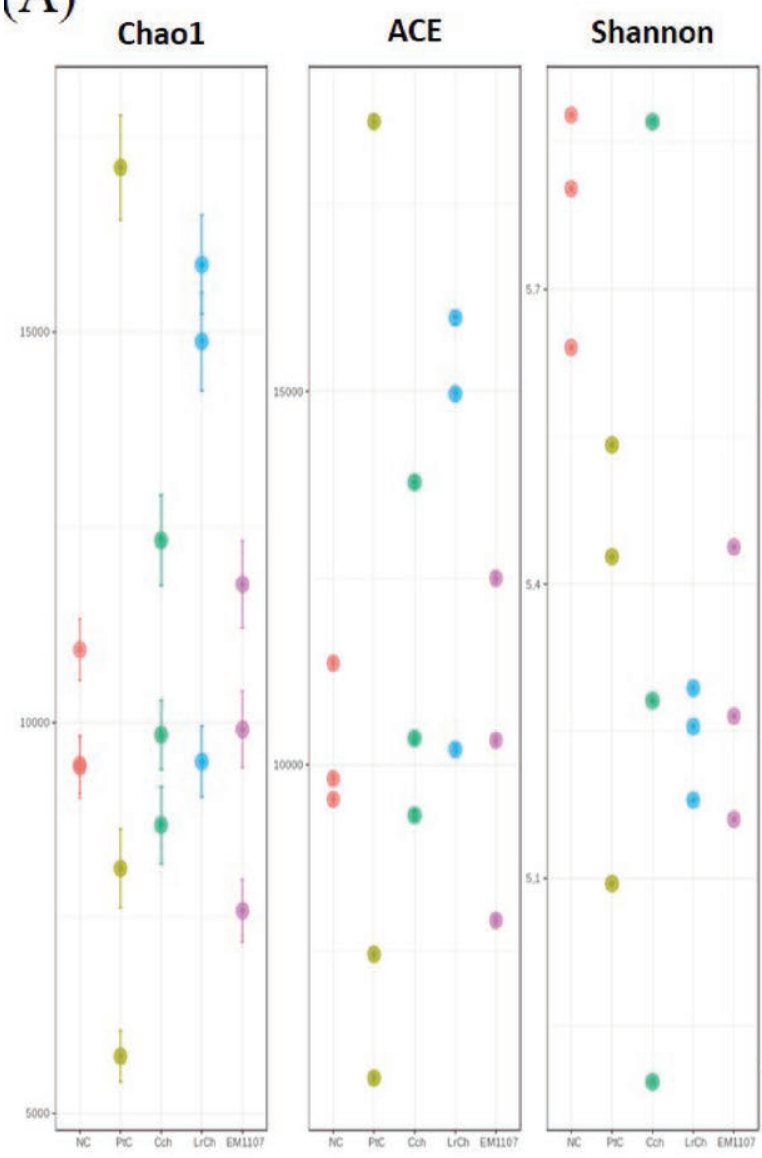

Simpson

InvSimpson

Fisher
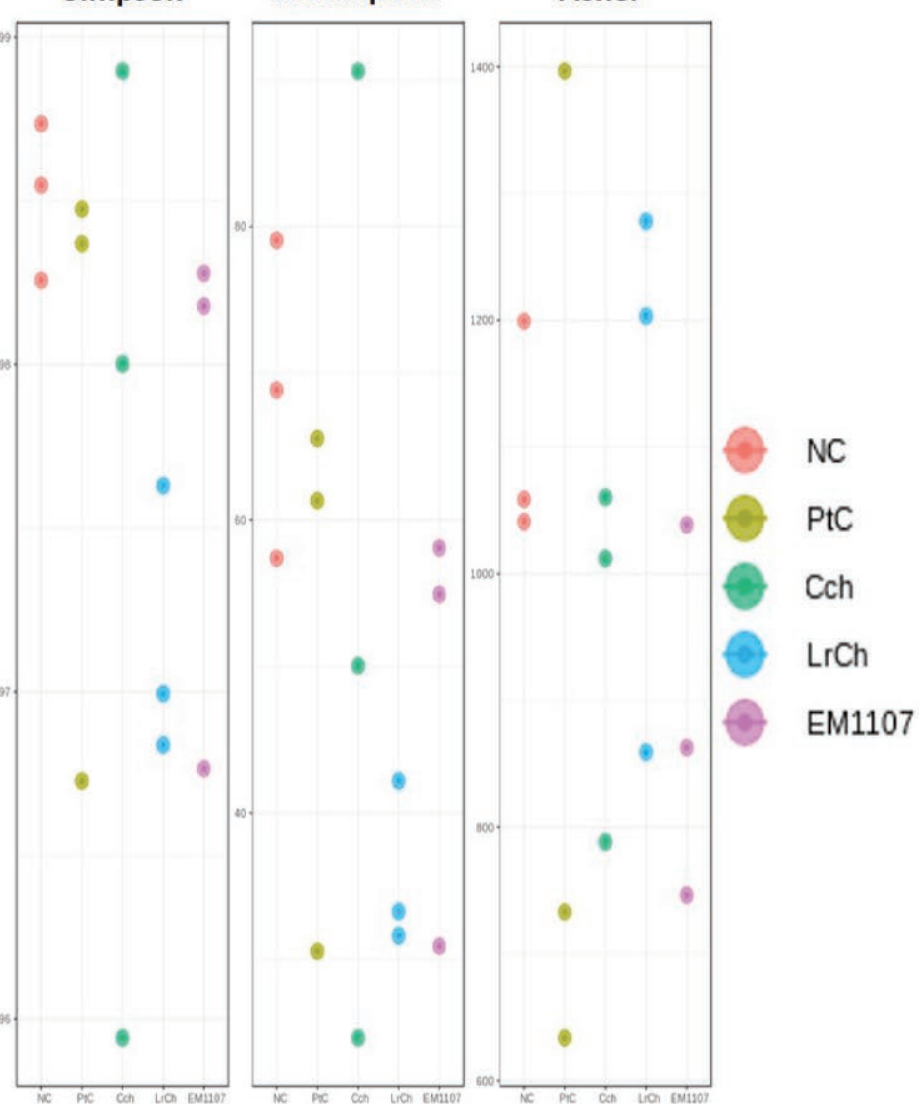

(B)

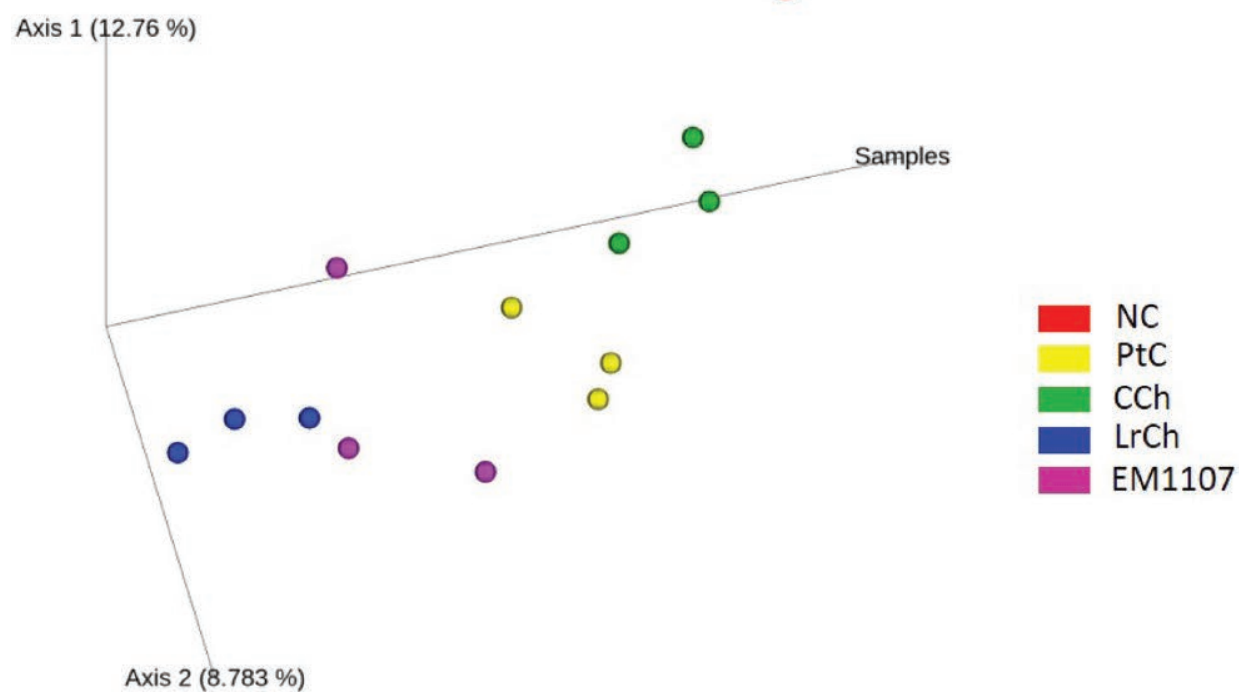

Figure 2. Microbial diversity in the cecum of rats under different dietary treatments: $\mathrm{NC}=$ negative control; PtC = positive control; CCh $=$ control cheese; $\mathrm{LrCh}=$ probiotic cheese; EM1107 = probiotic alone. (A) Plots showing $\alpha$ diversity determined by different indices: Chao1, ACE, Shannon, Simpson, InvSimpson, and Fisher. (B) Relative relatedness of the microbial community members according to the principal coordinate analysis with Bray-Curtis distance. 
In terms of genera (Figure 5), we highlight the marked increase in Blautia spp. in the feces of rats fed LrCh $(28.43 \%)$ and EM1107 $(23.47 \%)$ compared with CCh (13.5\%), PtC (11.26\%), and NC (6.75\%) groups. Variations in the abundance of Prevotella across the groups were also observed; $\mathrm{NC}$ and $\mathrm{CCh}$ groups showed similar abundances (32.69 and $31.43 \%$, respectively) compared with EM1107 (17.89\%), PtC (14.21\%), and LrCh (10.74\%).

Figure 6 presents the relative abundance of Lactobacillus spp among the experimental groups. Interestingly, rats in the LrCh group presented the highest Lactobacillus spp. abundance compared with the others. The results of the LEfSe analysis are shown in Figure 7, which presents OTU at different taxonomic levels that are significantly different between the $\mathrm{NC}$ and the other groups $(P<0.05)$.

\section{NF-KB Determinations}

At 1 DPI, the expression of NF- $\kappa \mathrm{B}$ was higher $(P<$ $0.05)$ in PtC compared with other groups. This difference was observed up to 4 DPI when compared with
CCh and EM1107 groups. Lower $(P<0.05)$ NF- $\kappa$ B levels were seen in rats fed $\mathrm{LrCh}$ compared with $\mathrm{PtC}$ at 8 DPI (Figure 8A).

\section{Cytokine Level}

The IL-1 $\beta$ and IFN- $\gamma$ levels were lower $(P<0.05)$ in EM1107 at 1 DPI compared with PtC. At 4 DPI, IFN- $\gamma$ was reduced $(P<0.05)$ in LrCh and EM1107 compared with PtC. On the last sampling day (8 DPI), TNF- $\alpha$ was lower in $\mathrm{CCh}$ and EM107 groups, whereas the IFN- $\gamma$ decreased in both of the experimental groups in which rats were fed cheese ( $\mathrm{CCh}$ and $\mathrm{LrCh}$ ) compared with PtC. No statistical difference was observed in IL10 levels among SE-inoculated groups (Figure 8B-E).

\section{MPO and MDA Determinations}

There was a reduction $(P<0.05)$ in MPO activity in EM1107 compared with PtC at 4 DPI. Higher levels $(P$ $<0.05)$ of MPO were observed in rats fed cheese $(\mathrm{LrCh}$ and $\mathrm{CCh}$ treatment groups) compared with $\mathrm{PtC}$ group. No difference was observed in MDA levels among the

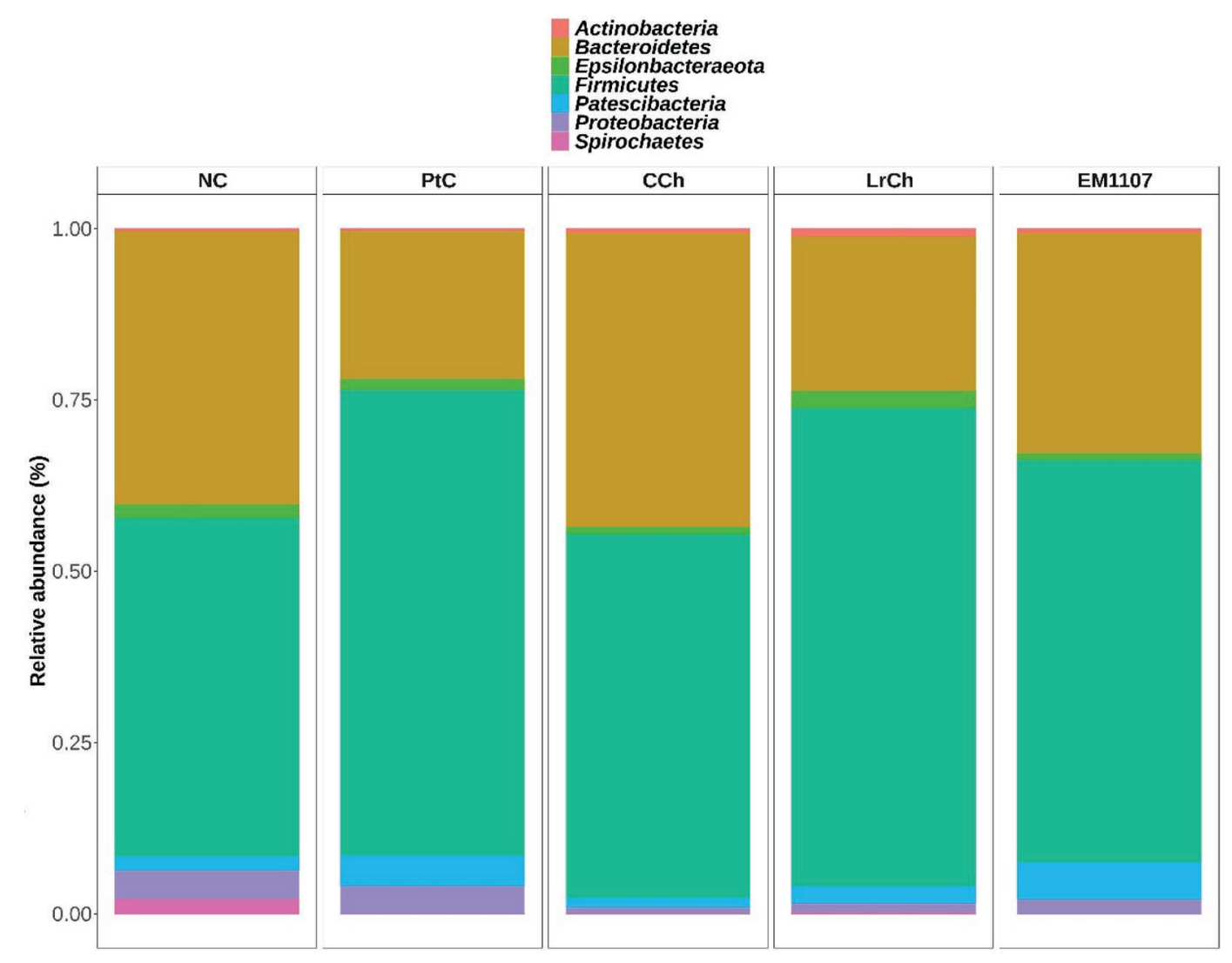

Figure 3. Effect of group treatments on the top 7 most abundant taxa at the phylum level. $\mathrm{NC}=$ negative control; PtC $=$ positive control; $\mathrm{CCh}=$ control cheese; $\mathrm{LrCh}=$ probiotic cheese; EM1107 = probiotic only. 


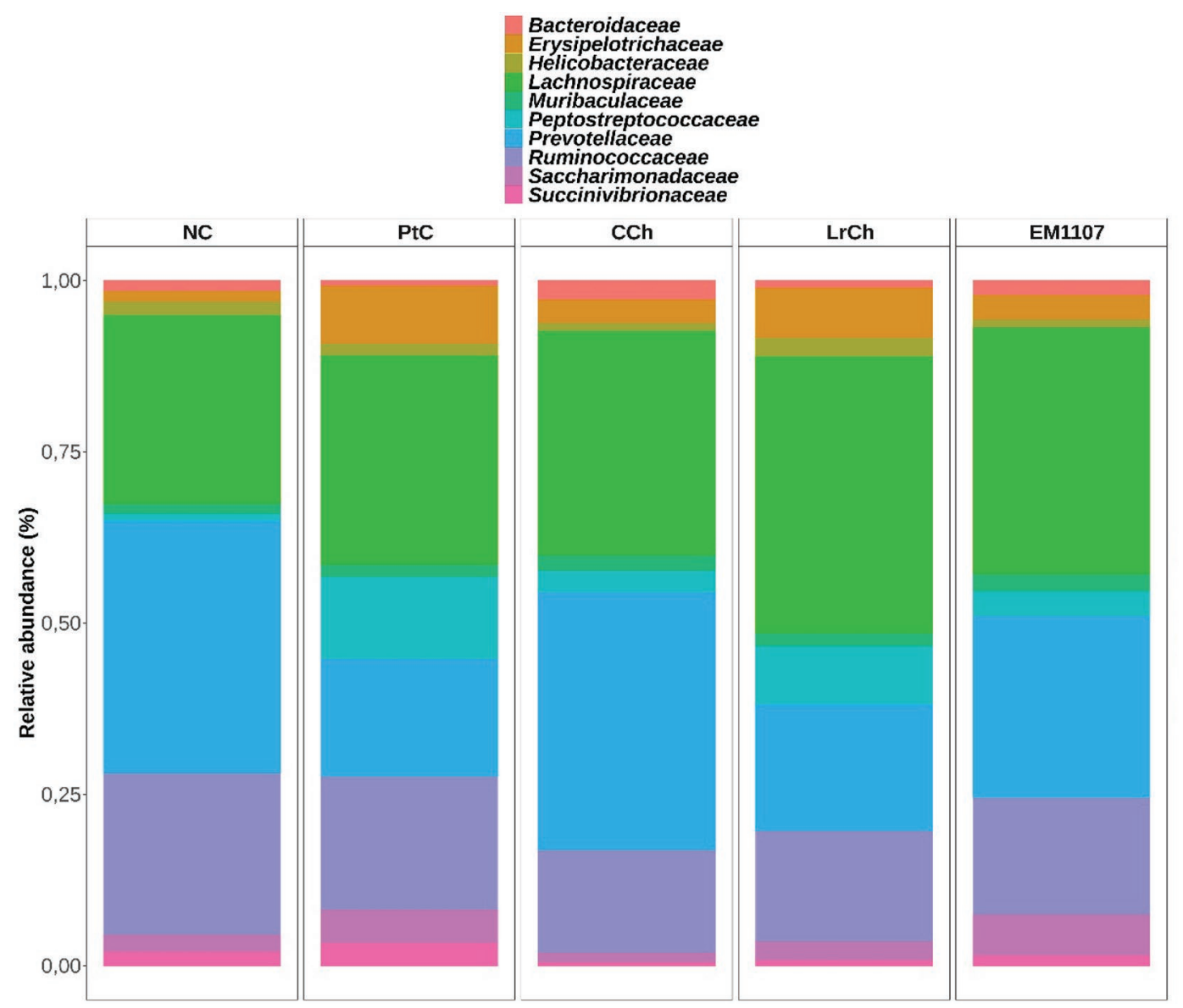

Figure 4. Effect of group treatments on the top 10 most abundant taxa at the family level. $\mathrm{NC}=$ negative control; PtC = positive control; $\mathrm{CCh}=$ control cheese; $\mathrm{LrCh}=$ probiotic cheese; EM1107 = probiotic only.

treatment groups, except for a reduction $(P<0.05)$ in EM1107 compared with PtC group at 4 and 8 DPI (Figure 9).

\section{Histopathology}

At the beginning of the inoculation (1 DPI), there was a reduction of neutrophilic inflammation in the cecum of rats from EM1107 group, with similar findings observed in healthy animals (NC). In the LrCh group, discrete lymphohistiocytic inflammation was observed in the cecal mucosa accompanied by discrete edema of the submucosa. The PtC animals presented diffuse lymphohistiocytic inflammation in the cecal mucosa accompanied by severe hemorrhage and submucosal edema (Figure 10). At 4 DPI, a slight multifocal lymphohistiocytic inflammation in the mucosa was found in in EM1107 animals, whereas the PtC group presented diffuse lymphohistiocytic inflammation in the cecal mucosa accompanied by edema of submucosa. Similar to EM1107, the LrCh group presented a reduction in tissue inflammation, with discrete lymphohistiocytic inflammation in the cecal mucosa accompanied by discrete submucosal edema, in contrast to PtC (Figure 11). Finally, there was an apparent improvement in lymphohistiocytic inflammation in the EM1107 group at $8 \mathrm{DPI}$, whereas there was a discrete improvement at the submucosa level in the LrCh group (Figure 12).

\section{DISCUSSION}

The findings of the present study indicate that $L$. rhamnosus EM1107 led to anti-inflammatory effects associated with the modulation of the immune system, reduced intestinal tissue damage, ameliorating the oxidative stress response induced by Salmonella infection in rats challenged with Salmonella Enteritidis. The administration of L. rhamnosus EM1107, either in a cheese matrix or alone, was able to reduce the intestinal SE colonization. A previous in vitro study showed that a probiotic Lactobacillus spp. strain (KSBT56) led to an inhibitory effect over Salmonella Enteritidis 
P125109 by decreasing its multiplication, adhesion, and invasion in colon epithelial cells, probably due to the production of lactic acid (Das et al., 2013). Lactobacillus spp. metabolize carbohydrates to produce lactic acid that decreases fecal $\mathrm{pH}$. It is possible the lower $\mathrm{pH}$ contributed to the reduced SE counts in the feces of rats receiving the probiotic strain (EM1107 and LrCh). Hydrogen peroxide, carbon dioxide, and antibacterial compounds, including bacteriocins and nonbacteriocins and nonlactic acid molecules can also be produced by LAB and could be detrimental to intestinal Salmonella strains (Marianelli et al., 2010; Zhang et al., 2018).

In addition, the presence of $\mathrm{SE}$ in the liver and spleen at the beginning of the infection in the animals of all SE-challenged groups confirms the invasiveness of the SE strain used in the present experiment. According to Finlay and Brumell (2000), SE can cross the lining of intestinal epithelial cells and translocate to extraintestinal organs such as the spleen and liver. Salmonella's capacity to cross the gut barrier, spread to other organs, and survive in host defense cells, such as macrophages and dendritic cells, is attributed to the Salmonella pathogenicity island I and II, respectively, which encode for genes that allow enterocyte invasion and bacterial proliferation in extraintestinal tissue and therefore cause systemic infections (Silva et al., 2012; Foley et al., 2013). According to our model, the treatment with L. rhamnosus EM1107 had no effect on the

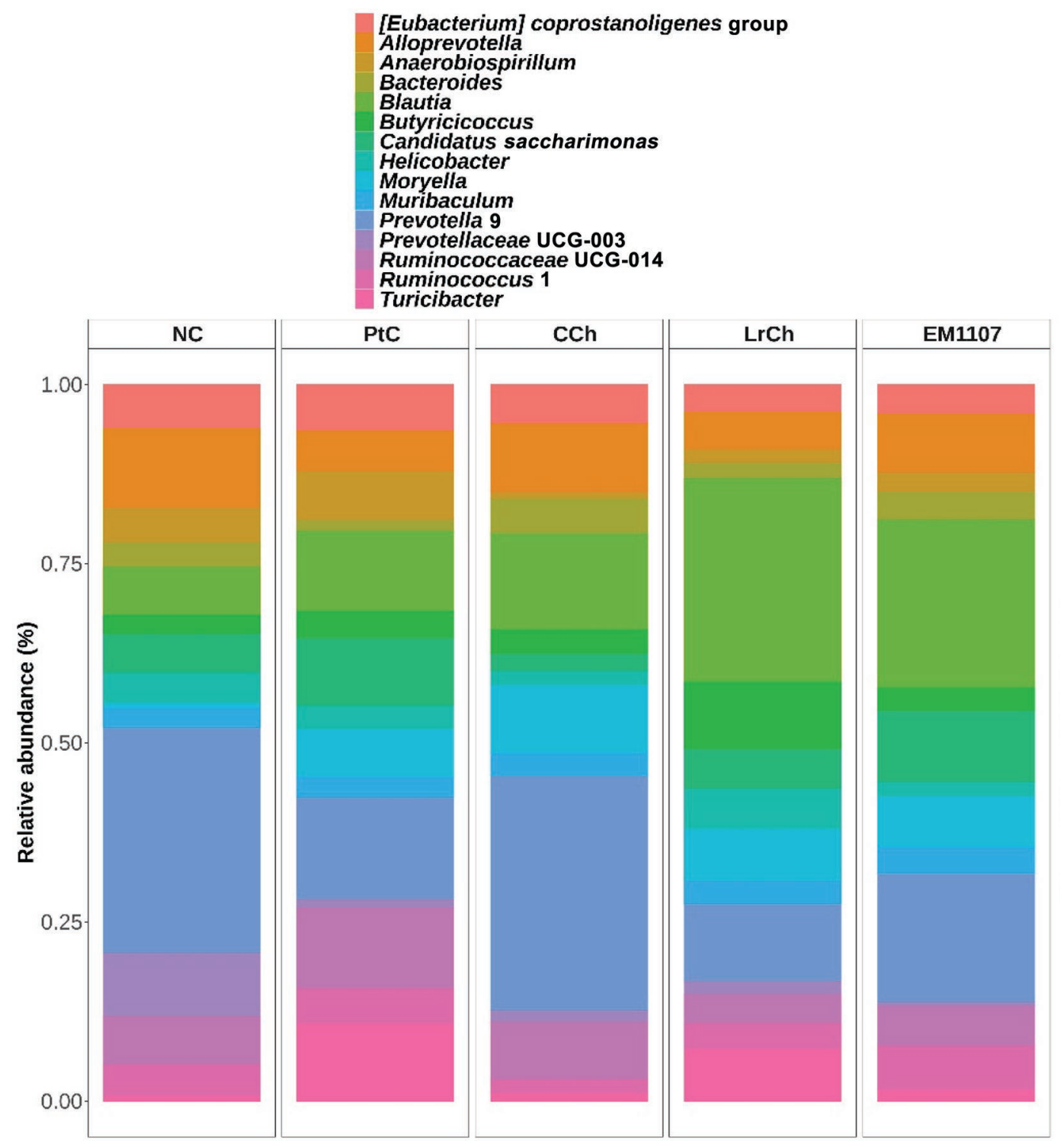

Figure 5. Effect of group treatments on the top 15 most abundant taxa at the genus level. $\mathrm{NC}=$ negative control; PtC $=$ positive control; $\mathrm{CCh}=$ control cheese LrCh $=$ probiotic cheese; EM1107 = probiotic only. 


\section{Lactobacillus}

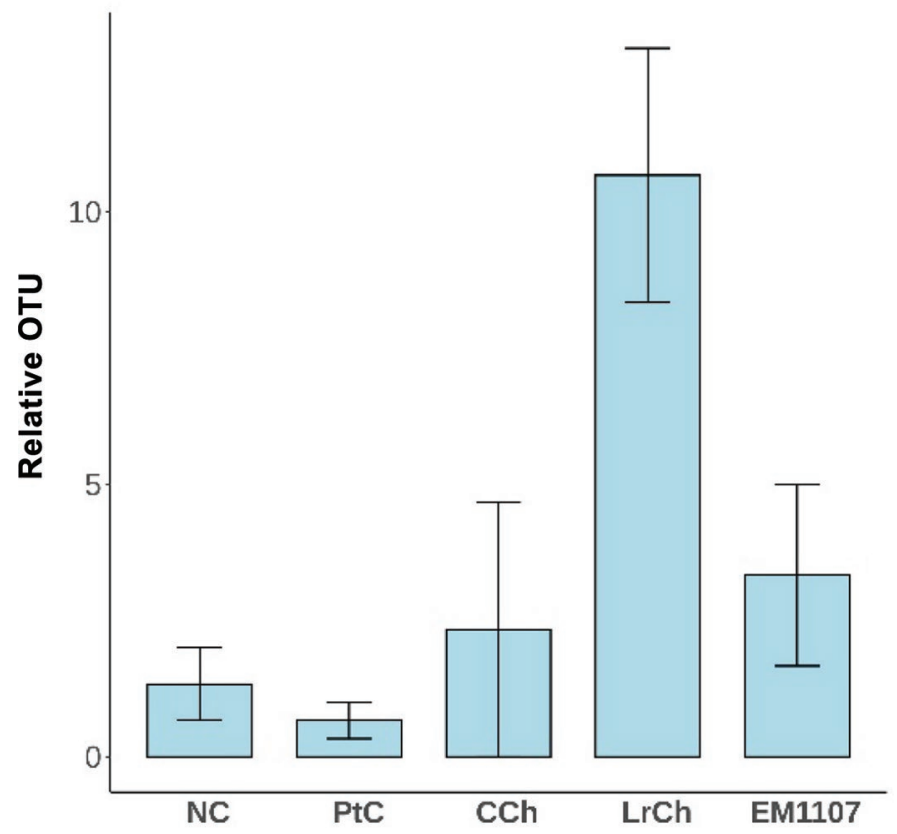

Figure 6. Effect of administration of treatments on the relative operational taxonomic unit (OUT) counts related to Lactobacillus spp. across the different treatment groups. $\mathrm{NC}=$ negative control; $\mathrm{PtC}$ $=$ positive control; $\mathrm{CCh}=$ control cheese; $\mathrm{LrCh}=$ probiotic cheese; EM1107 = probiotic alone. Data are expressed as mean \pm SEM.

systemic survival of SE promoted by Salmonella pathogenicity island II.

In terms of gut microbial diversity, the $16 \mathrm{~S}$ rRNA sequencing analysis revealed that L. rhamnosus EM1107 led to significant changes in the gut microbiota of rats toward a reduced evenness and increased richness compared with the sham treatment (NC; Figure 2). This finding is probably related to the antimicrobial effects of the probiotic strain, which plays a role as a rare specimen in the colonization of the gut. The LABsupplemented feed is associated with significant shifts in gut microbiome in different species, such as shrimp (Sha et al., 2016) and chicken (Wang et al., 2017). In terms of $\beta$-diversity, the dissimilarities between $\mathrm{NC}$ and the other treatments, mostly with the LrCh group, indicate that the insertion of an alien bacterium strain into the gut can cause a switchover into the microbial composition to the point of decreasing the microbial relatedness in each community (Figure 2). According to our data, the NC group presented a higher diversity of OTU compared with the other treatments (Figure 6).

The L. rhamnosus strain EM1107 favored the growth of some commensal bacteria, such as those belonging to the family Lachnospiraceae and the genus Blautia (Figures 4 and 5). Lachnospiraceae are abundant gut commensal organisms and are consistently depleted in people with intestinal diseases, suggesting that these organisms are important to maintain intestinal homeostasis (Suchodolski, 2013). Reeves et al. (2012) demonstrated that Lachnospiraceae strains were able to partially restore eubiosis in response to Clostridium difficile postinfection and improve clinical status in germfree mice. According to Jenq et al. (2015), Blautia spp. are associated with reduced lethal graft-versushost disease and negatively correlated with poor health conditions, such as malnutrition (Million et al., 2016), irritable bowel syndrome (Weinberg et al., 2018), and early-stage breast cancer patients (Luu et al., 2017).

We observed that cheese probably served as a Prevotella source for mice gut colonization (Figure 5). Milk is considered an important source of Prevotella organisms in consumers, as has been reported in several species (Brink et al., 2019; Petrullo et al., 2019). The higher abundance of Lactobacillus in rats fed cheese (Figure 6) corroborates our hypothesis that cheese serves as a protective matrix for L. rhamnosus EM1107. Compared with other dairy products, cheese represents a better matrix favoring $\mathrm{LAB}$, attributed to its chemical and physical properties such as less acidic environment, high buffering capacity and low oxygen contents due to the solid matrix composed both of high fat and protein contents (Cichosz et al., 2014; Haman and Ahmed, 2019).

Previous studies have shown that the consumption of probiotic-added dairy products leads to beneficial microbial effects in hosts affected by several clinical disorders. Nonfermented dairy products with added Lactobacillus spp. may halt dysbiosis associated with penicillin after administration, and therefore prevent Clostridium spp. overgrowth (Korpela et al., 2016). Moreover, dairy products supplemented with probiotics may favor the growth of butyrate-producing strains, which lead to amelioration of autoimmune illnesses such as atopic dermatitis (Jong-Hwa et al., 2019).

The reduced expression of NF-kB in EM1107 animals at 1 and 4 DPI (Figure 8) was probably associated with the decrease in TNF- $\alpha$, IL- $1 \beta$, and IFN- $\gamma$. Similarly, the reduction of the levels of NF-kB in the LrCh group, which occurred on 1 and 8 DPI, can explain lower cytokine levels at 1 (TNF- $\alpha), 4$ (IL-1 $\beta$ and IFN- $\gamma$ ), and 8 DPI (IFN- $\gamma)$. Minor differences in the cytokine expression patterns between EM1107 and LrCh groups may be attributed to the effects of the lactic matrix. Interestingly, lower levels of NF-kB expression were observed in the CCh group from 1 to 4 DPI, with consequent reduction in TNF- $\alpha$ levels at 1 and 8 DPI, IL- $1 \beta$ at 4 DPI, and IFN- $\gamma$ at 8 DPI. Our results corroborate a previous study using the same probiotic strain (Rodrigues et al., 2018), which reported a reduction in the expression of NF-k $\beta$, TNF- $\alpha$, and IL- $1 \beta$ in 
rats receiving the probiotic strain alone or added to a cheese matrix.

Invasive pathogens, such as Salmonella, stimulate the induction of the innate host immune response. The intestinal endothelium detects the presence of the invader through receptors and begins activation of mitogenactivated protein kinase that induces gene expression of transcription factors such as activating protein 1 and NF-kB. This results in the production of pro-inflammatory cytokines IL-18 and IL-12, which stimulate the activation of type 1 helper cells that in turn synthesize IFN- $\gamma$, increasing phagocyte activity and destruction of internalized bacteria. Interleukin- $1 \beta, \mathrm{TNF}-\alpha$, and IL-23 recruit neutrophils that are responsible for the defense of extracellular bacteria (Santos et al., 2009; Thiennimitr et al., 2011). In contrast, the use of probiotics can modulate different pro-inflammatory cytokine profiles, such as TNF- $\alpha$, IFN- $\gamma$, and IL- $1 \beta$, and antiinflammatory cytokines, such as IL-10 and IL-4, which may promote improved host immune response against invasion by pathogens such as Salmonella (Castillo et al., 2012; Alvim et al., 2016).

In the present study, there was a reduction in MPO activity during infection (4 DPI) in the EM1107 group compared with PtC (Figure 9). Therefore, EM1107 could reduce the effects of inflammatory stress. On the other hand, MPO activity was higher both in the $\mathrm{CCh}$ and LrCh groups (Figure 9). As a consequence of TNF- $\alpha$ induction by SE, neutrophil infiltration into the epithelium generates the release of MPO, an enzyme responsible for the overproduction of reactive oxygen species that causes a decrease in intestinal antioxidant defenses, such as glutathione (de Moreno de LeBlanc and Perdigón, 2010). Furthermore, it triggers an increase in the production of MDA, a secondary product of lipid peroxidation.

Although the histopathological findings revealed a reduction in the gut inflammation observed in $\mathrm{CCh}$ and EM1107 groups compared with the PtC (Figures 10, 11, and 12), there was no direct correlation with MPO activity, either at the beginning or the end of evaluated periods (Figure 9). Similar results have been reported by de Moreno de LeBlanc and Perdigón (2010). In addition, the amelioration of tissue inflammation in rats fed cheese could be also associated with the presence of glutathione peroxidase in goat milk, which is part of a defense system against pathogenic microorganisms (Slačanac et al., 2010).

Malondialdehyde is a parameter for assessing oxidative stress caused by tissue inflammation. This is

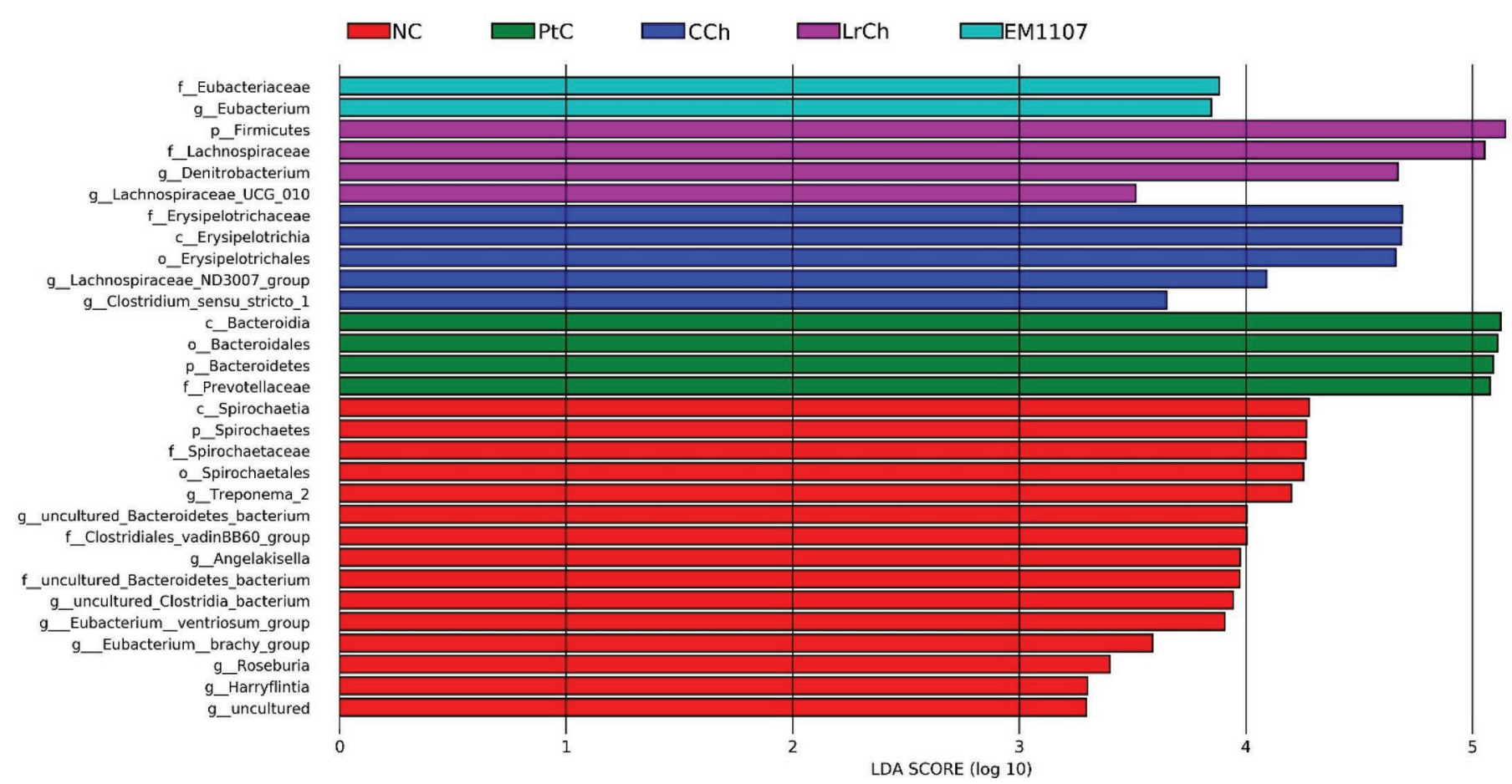

Figure 7. Discriminative operational taxonomic units at different taxonomic levels between treatment groups, according to linear discriminant analysis effect size. $\mathrm{NC}=$ negative control; $\mathrm{PtC}=$ positive control; $\mathrm{CCh}=$ control cheese; $\mathrm{LrCh}=$ probiotic cheese; EM1107 $=$ probiotic alone; $\mathrm{f}_{-}=$family; $\mathrm{g}_{-}=$genus; $\mathrm{p}_{-}=$phylum; $\mathrm{c}_{-}=$class; $\mathrm{o}_{-}=$order. 
(A1) NF-kB d 1 post-infection

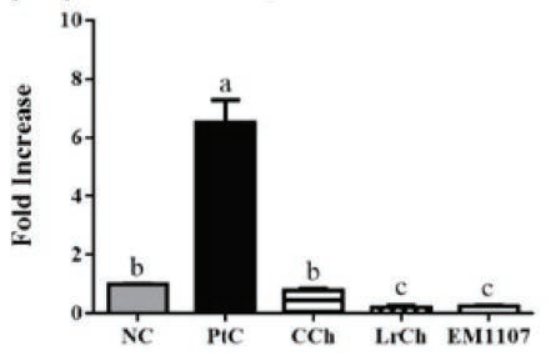

(B1) IL-1 $\beta \mathrm{d} 1$ post-infection

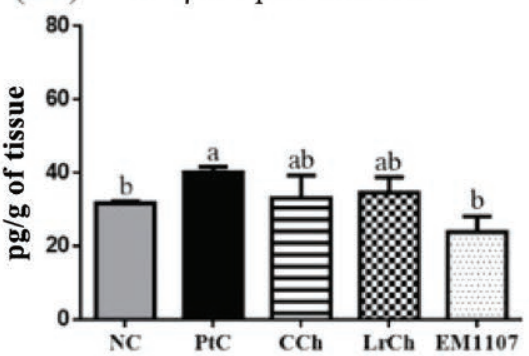

(C1) TNF- $\alpha$ d 1 post-infection
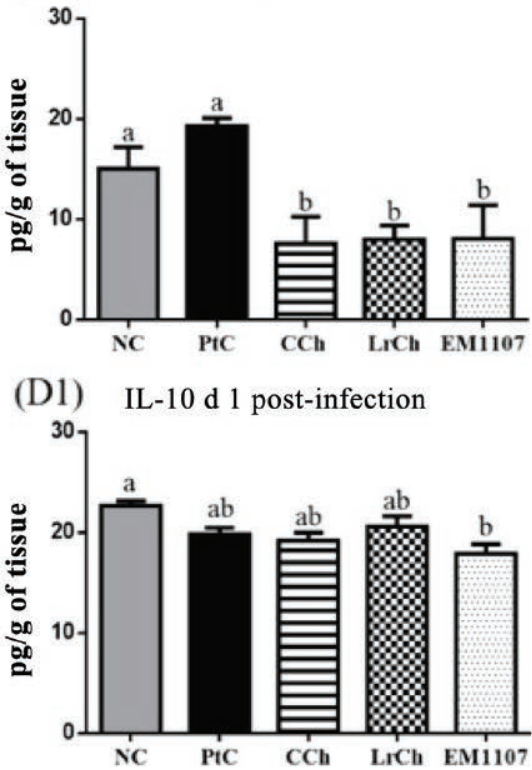

(E1) INF- $\gamma d 1$ post-infection

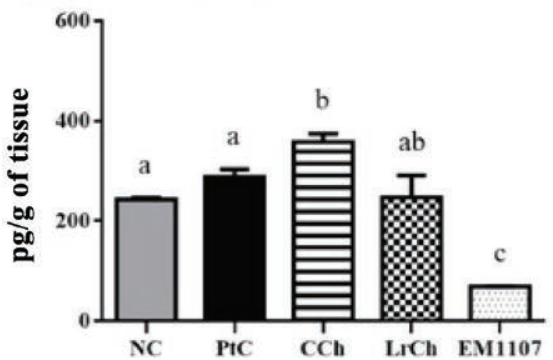

(A4) NF-kB d 4 post-infection

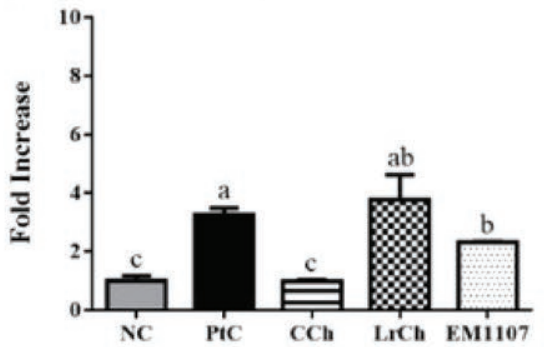

(B4) IL-1 $\beta \mathrm{d} 4$ post-infection

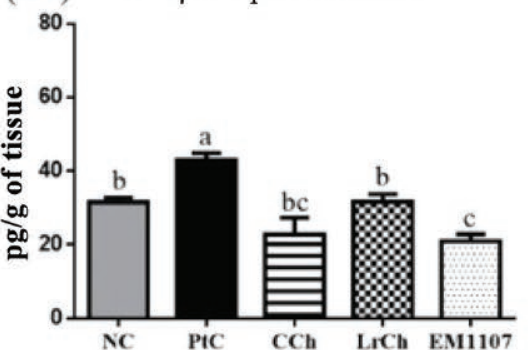

(C4) TNF- $\alpha$ d 4 post-infection

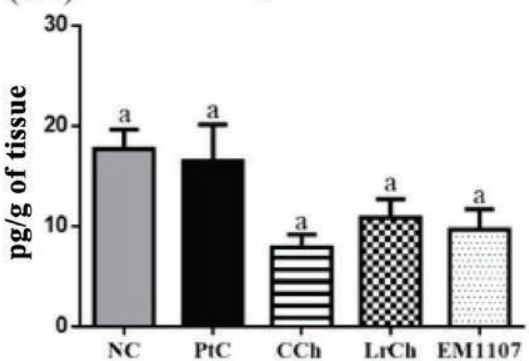

(D4) IL-10 d 4 post-infection

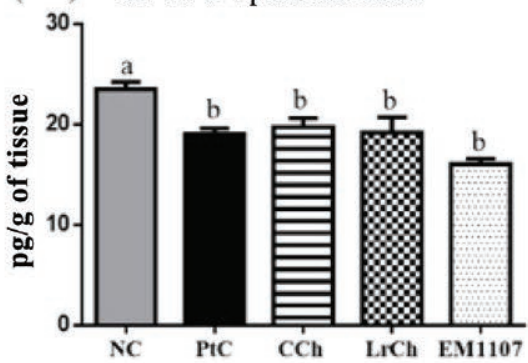

(E4) INF- $\gamma$ d 4 post-infection

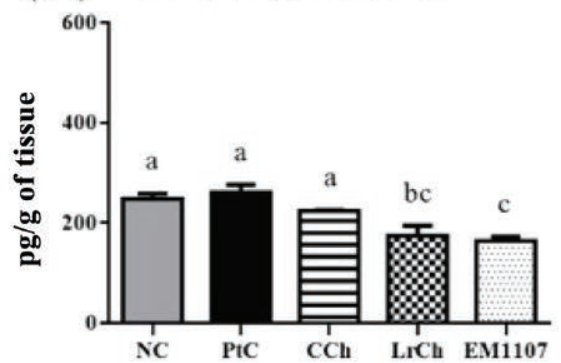

(A8) NF-kB d 8 post-infection

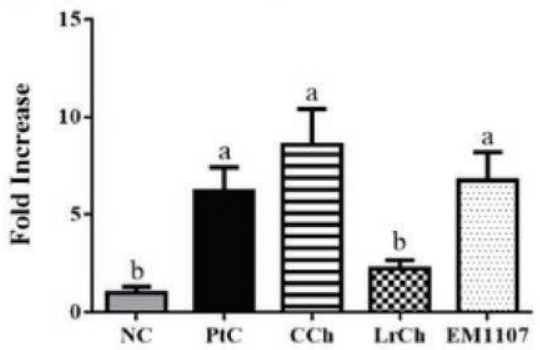

(B8) IL-1 $\beta \mathrm{d} 8$ post-infection

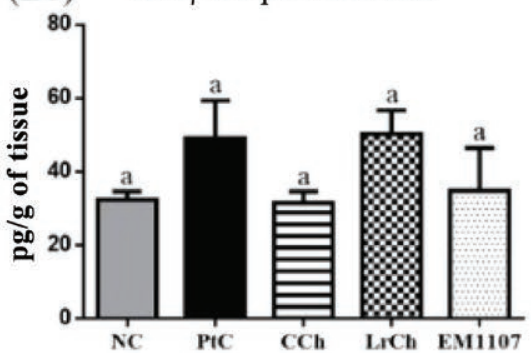

(C8) TNF- $\alpha$ d 4 post-infection
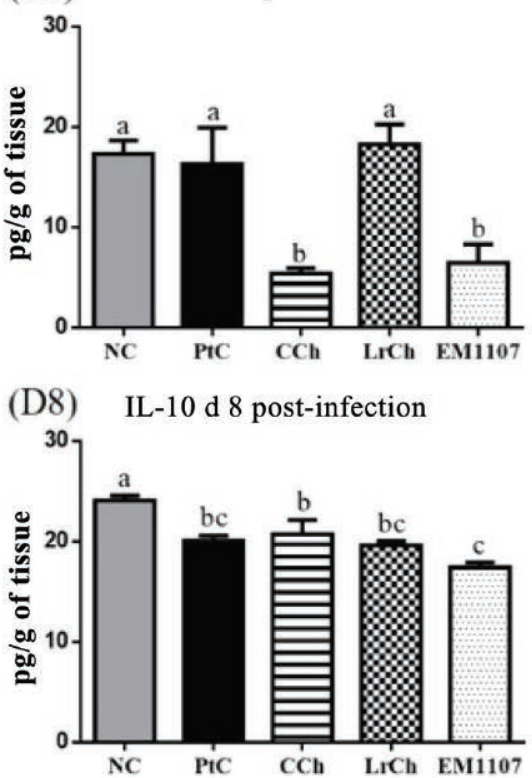

(E8) INF- $\gamma$ d 8 post-infection

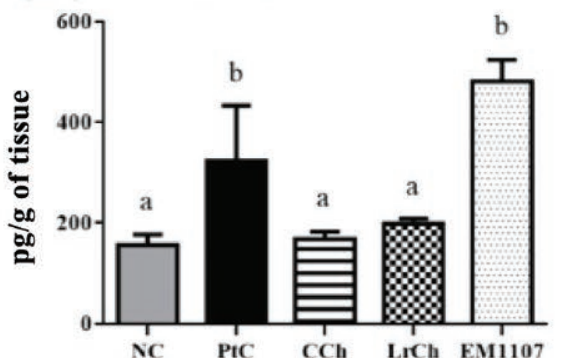

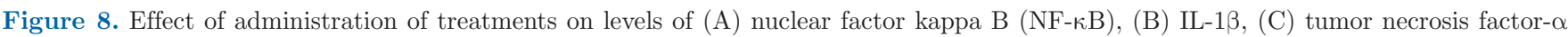
(TNF- $\alpha$ ), (D) IL-10, and (E) INF- $\gamma$ of cecal tissues in euthanized animals 1,4 , and $8 \mathrm{~d}$ after salmonellosis infection. Data are expressed as mean \pm SEM. Different letters $(\mathrm{a}-\mathrm{c})$ indicate significant differences $(P<0.05) . \mathrm{NC}=$ negative control; $\mathrm{PtC}=$ positive control; $\mathrm{CCh}=\mathrm{control}$ cheese; $\mathrm{LrCh}=$ probiotic cheese; EM1107 = Lactobacillus rhamnosus EM1107. 
because increased free radicals cause a higher concentration of MDA, a secondary product of lipid peroxidation, which can cause DNA damage, resulting in lysis and cell death (Rodrigues et al., 2018). In the present study, there was a reduction in MDA levels throughout the course of infection (4 and 8 DPI) in the EM1107 group compared with $\mathrm{PtC}$. These results demonstrate that the probiotic strain administered alone was able to reduce intestinal oxidative stress. Our results support previous findings showing MDA reduction in rats receiving EM1107 and submitted to the ulcerative colitis (Rodrigues et al., 2018).

The inflammatory features observed in the cecum of the PtC group animals were typical SE responses described in various studies. These responses were characterized by enterocolitis with infiltration of polymorphonuclear leukocytes, and presence of edema, hemorrhages, and epithelial erosion (Haraga et al., 2008; Santos et al., 2009). A general reduction in inflammation was observed in rats from EM1107, LrCh, and $\mathrm{CCh}$ groups compared with $\mathrm{PtC}$ group throughout the experimental period (Figure 8). Moreover, the histological findings in the animals from EM1107 and $\mathrm{LrCh}$ groups were similar to those observed in $\mathrm{NC}$ group at 1 , and 4 DPI, respectively (Figures 10, 11, and 12). De Moreno de LeBlanc et al. (2010) reported no inflammation but only increased lymphohistiocytic infiltration in rats receiving Lactobacillus casei 431 for $7 \mathrm{~d}$ after they had been challenged with Salmonella Typhimurium. Similarly, Kemgang et al. (2016) observed a significant improvement in villi structure of animals fed L. rhamnosus S1K3, 5 to 20 DPI. The protective action of probiotics in minimizing tissue damage caused by Salmonella has also been reported (Asahara et al., 2011; Castillo et al., 2013; Noto Llana et al., 2013).

According to similar study using a chemically induced colitis model (Rodrigues et al., 2018), EM1107 treatment increased the expression of mucin 2, indicating mucus as a protective factor for the gut epithelium against SE colonization and invasiveness. Although goat cheese reduced the tissue damage caused by SE, no synergic effect on inflammation status was observed by adding EM1107 in the form of a probiotic cheese.

\section{CONCLUSIONS}

Cheese supplemented with L. rhamnosus EM1107 strain was able to reduce Salmonella colonization, de-
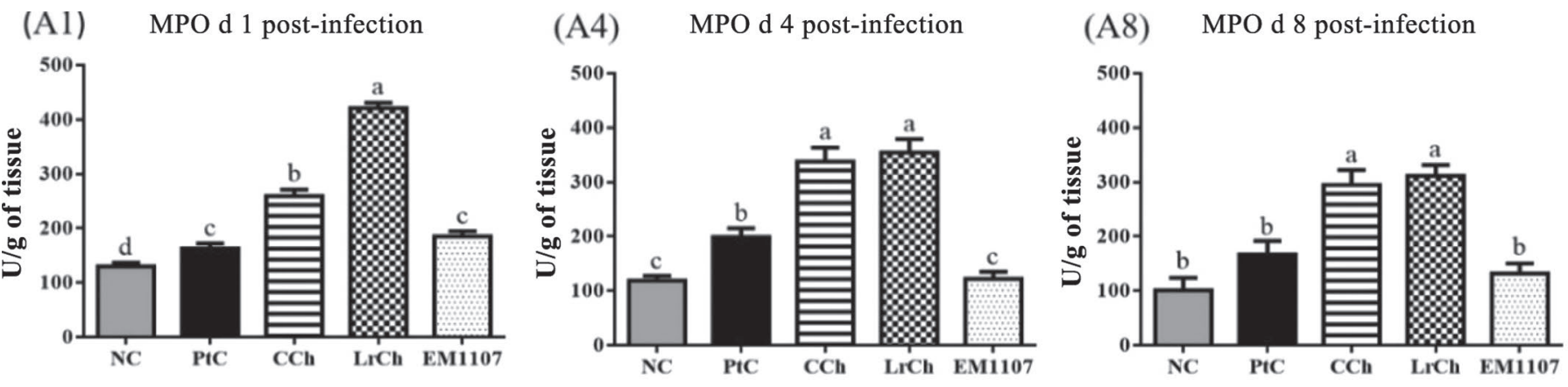

(B1)

MDA d 1 post-infection

MDA d 4 post-infection
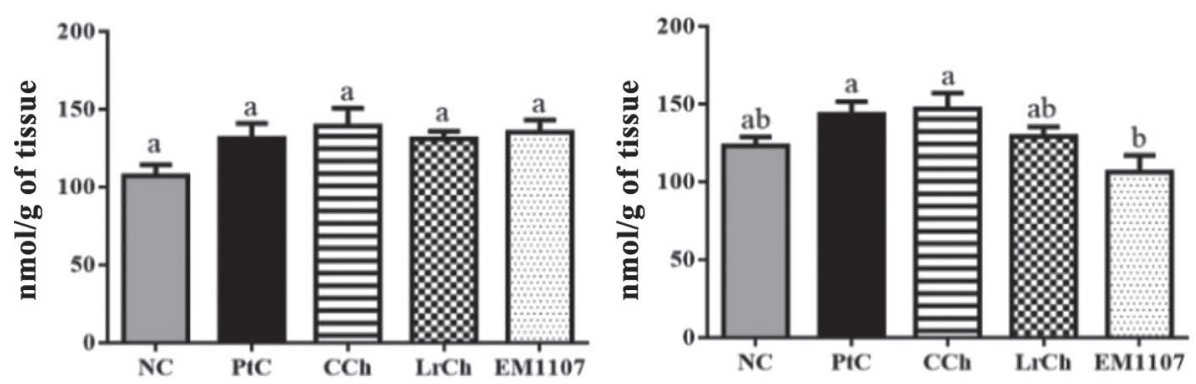

(B8) MDA d 8 post-infection

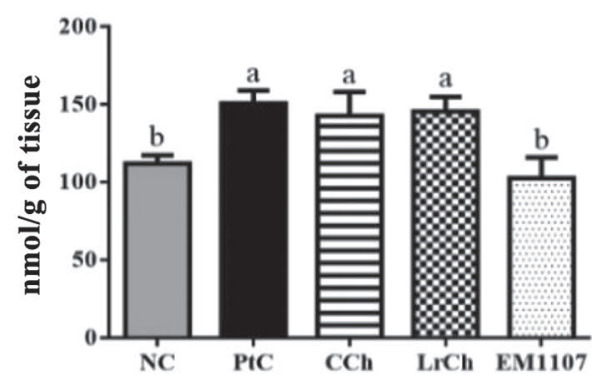

Figure 9. Effect of administration of treatments on (A) myeloperoxidase (MPO) activity and (B) malondialdehyde (MDA) content in cecal tissues of euthanized animals 1,4 , and $8 \mathrm{~d}$ after salmonellosis infection. Data are expressed as mean \pm SEM. Different letters (a-d) indicate significant differences $(P<0.05) . \mathrm{NC}=$ negative control; $\mathrm{PtC}=$ positive control; $\mathrm{CCh}=$ control cheese; $\mathrm{LrCh}=$ probiotic cheese; $\mathrm{EM} 1107=$ Lactobacillus rhamnosus EM1107. 
crease the production of pro-inflammatory cytokines, and reduce tissue damage in the intestinal lumen of rats at early stages of infection. Although the administration of L. rhamnosus EM1107 alone provided protec- tive effects against SE, the use of cheese as a vehicle for L. rhamnosus EM1107 resulted in a more pronounced shift in the microbial composition, favoring beneficial organisms such as Blautia and Lactobacillus.

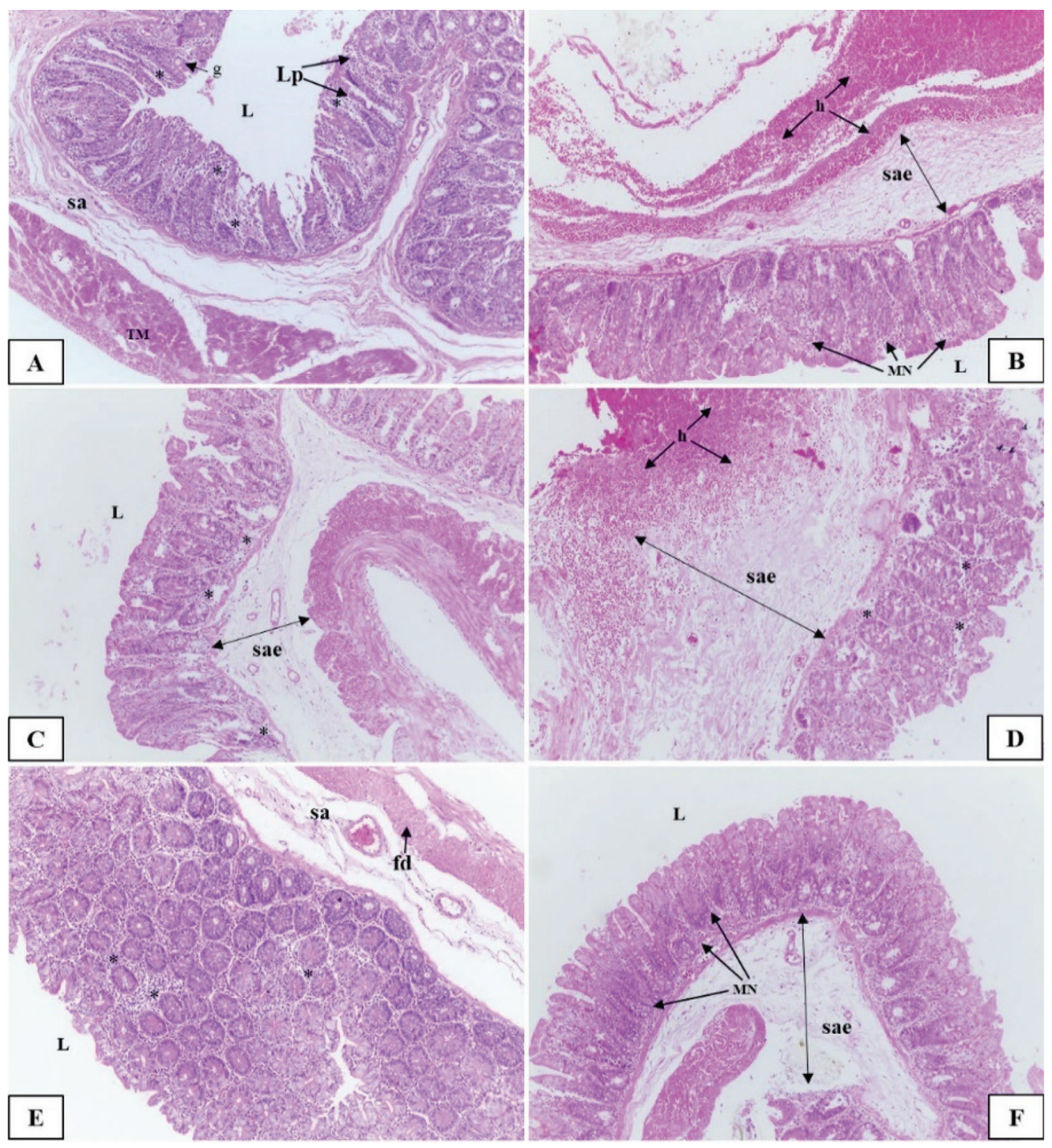

Figure 10. Histopathological analysis of Wistar rat ceca on the first day after challenge with Salmonella Enteritidis P125109 with different degrees of typhlitis. (A) Mild neutrophilic inflammation of the cecum, in addition to submucosal edema in animals of the negative control group. (B) Diffuse lymphohistiocytic inflammation in the cecal mucosa accompanied by severe hemorrhage and submucosal edema in positive control group animals. (C) Focal and discrete neutrophilic and lymphohistiocytic inflammation in the cecal mucosa with edema in the submucosa of the control cheese group. (D) Focal and discrete neutrophilic and lymphohistiocytic inflammation in the cecal mucosa with marked hemorrhage and edema in the submucosa of the control cheese group. (E) Discrete multifocal neutrophilic inflammation in the cecum mucosa with slight degeneration of smooth muscle fibers from the Lactobacillus rhamnosus EM1107 group. (F) Mild lymphohistiocytic inflammation in the cecal mucosa accompanied by mild submucosal edema of the animals of the probiotic cheese group. $\mathrm{L}=$ cecal lumen; $\mathrm{Lp}=$ lamina propria; $\mathrm{g}=$ goblet cells; $\mathrm{sa}=$ submucosa; $\mathrm{TM}=$ muscular tunic; $\mathrm{h}=$ hemorrhage; sae = submucosa edema; $\mathrm{MN}=$ lymphohistiocytic or lymphohistioplasmicocyte infiltrate; $\mathrm{fd}=$ degeneration of smooth muscle fibers. * indicates neutrophilic infiltrate. H\&E coloring (Merck, Darmstadt, Germany). Magnification $=100 \times$. 


\section{ACKNOWLEDGMENTS}

The authors thank Maria Lúcia da Conceição for support in the microbiological analysis in the Laboratory of Microbiology of Food (Department of Nutrition,
Center of Sciences of the Health, Federal University of Paraíba, João Pessoa, Brazil) and graduate students Karol Sampaio, Luana Martiniano, Camila Neves, Eduarda Marinho, Pedro Jusselino and Matheus Estrela (Federal University of Paraíba, João Pessoa, Brazil).

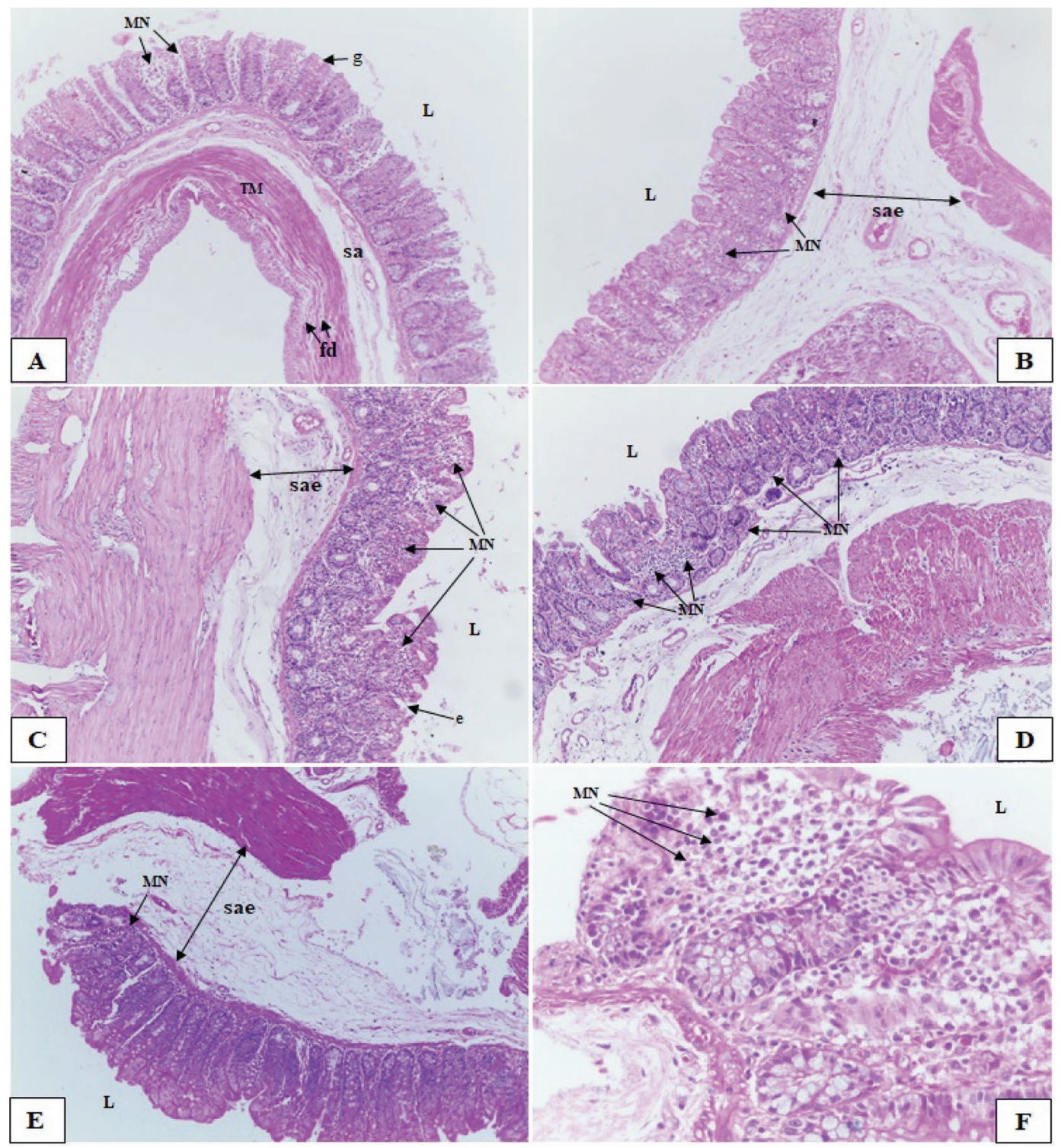

Figure 11. Histopathological analysis of Wistar rat ceca on d 4 after challenge with Salmonella Enteritidis P125109 with different degrees of typhlitis. (A) Focal lymphohistiocytic inflammation in the cecum mucosa of animals of the negative control group. Magnification $=100 \times$. (B) Diffuse lymphohistiocytic inflammation in the cecal mucosa accompanied by submucosal edema in positive control group animals. Magnification $=100 \times$. (C) Lymphohistiocytic inflammation and slight erosion of the epithelium in the cecal mucosa with slight edema in the submucosa of the animals of the control cheese group. Magnification $=100 \times$. (D) Discrete multifocal lymphohistiocytic inflammation in the cecum mucosa of animals of the Lactobacillus rhamnosus EM1107 group. Magnification $=100 \times$. (E) Discrete lymphohistiocytic inflammation in the cecal mucosa accompanied by slight edema of the submucosa of the animals of the probiotic cheese group. (F) Inflammatory lymphohistiocytic infiltrate in the lamina propria of the animals of the probiotic cheese group evidenced at greater magnification $(400 \times)$. $\mathrm{L}=$ cecal lumen; $\mathrm{g}=$ goblet cells; sa $=$ submucosa; $\mathrm{TM}=$ muscular tunic; $\mathrm{h}=$ hemorrhage; sae = submucosa edema; $\mathrm{MN}=$ lymphohistiocytic or lymphohistioplasmicocyte infiltrate; $\mathrm{e}=$ erosion of the lining epithelium; $\mathrm{fd}=$ degeneration of smooth muscle fibers. H\&E coloring (Merck, Darmstadt, Germany). 

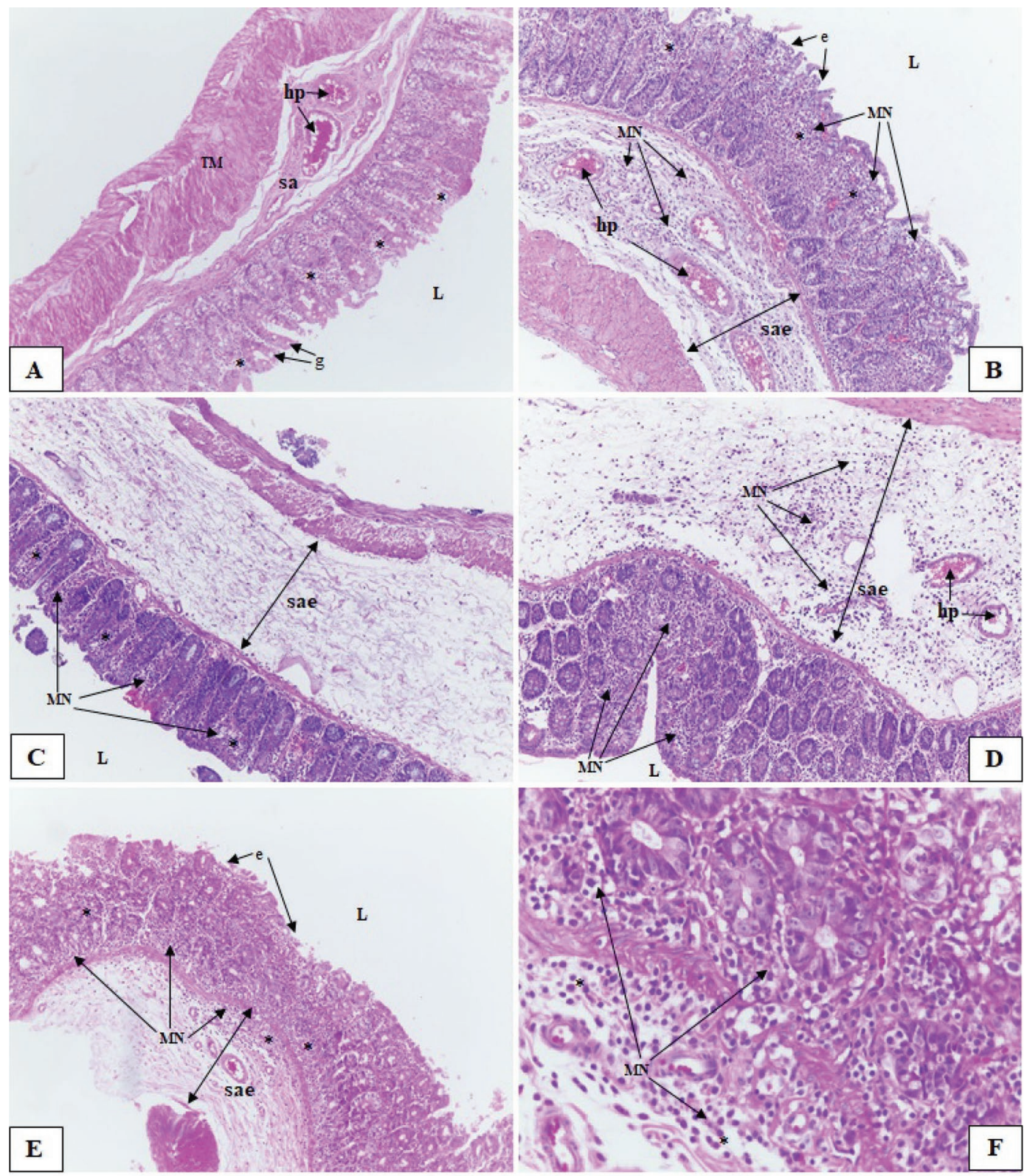

Figure 12. Histopathological analysis of Wistar rat ceca on d 8 after challenge with Salmonella Enteritidis P125109 with different degrees of typhlitis. (A) Discrete multifocal neutrophilic inflammation in the cecal mucosa and hyperemia in the submucosa of animals in the negative control group. Magnification: $100 \times$. (B) Moderate diffuse neutrophilic and lymphohistiocytic inflammation in the cecal mucosa, as well as multifocal erosion of the epithelium and lymphohistioplasmic cell inflammation with diffuse edema in the submucosa of positive control group animals. Magnification: $100 \times$. (C) Multifocal neutrophilic and lymphohistiocytic inflammation in the cecum mucosa with diffuse edema in the submucosa of the control cheese group animals. Magnification $=100 \times$. (D) Discrete multifocal lymphohistiocytic inflammation in the cecum mucosa and lymphohistiocytic inflammation, in addition to diffuse edema with focal hyperemia in the submucosa of animals of the Lactobacillus rhamnosus EM1107 group. Magnification: 100×. (E) Diffuse neutrophilic and lymphohistiocytic inflammation, as well as erosion of the cecal mucosal epithelium accompanied by mild lymphohistioplasmicocyte infiltrate and edema in the submucosa of the animals of the probiotic cheese group; probiotic cheese group evidenced at higher magnification $(400 \times) . \mathrm{L}=$ cecal lumen; $\mathrm{g}=$ goblet cells; sa $=$ submucosa; TM $=$ muscular tunic; $\mathrm{hp}=$ hyperemia; sae = submucosa edema; $\mathrm{MN}=$ lymphohistiocytic or lymphohistioplasmicocyte infiltrate; e $=$ erosion of the lining epithelium. ${ }^{*}$ indicates neutrophilic infiltrate. H\&E coloring (Merck, Darmstadt, Germany).

This work was supported by the EMBRAPA (Cod 02.09.01.024.00.00), Coordenação de Aperfeiçoamento de Pessoal de Nível Superior - Brazil (CAPES), Brazil (Finance Code 001) and Financiadora de estudos e
Projetos (FINEP). All procedures were approved by the Animal Ethics Committee of the Federal University of Paraíba (CEUA/UFPB- protocol no. 021/2016) following the National Institutes of Health (Bethesda, 
MD) guide for the care and use of laboratory animals (NIH Publications No. 8023, revised 1978). The authors declare no conflict of interest.

\section{REFERENCES}

Acurcio, L. B., R. W. Bastos, S. H. C. Sandes, A. C. C. Guimarães, C. G. Alves, D. C. dos Reis, S. Wuyts, A. C. Nunes, G. D. Cassali, S. Lebeer, M. R. de Souza, and J. R. Nicoli. 2017. Protective effects of milk fermented by Lactobacillus plantarum B7 from Brazilian artisanal cheese on a Salmonella enterica serovar Typhimurium infection in BALB/c mice. J. Funct. Foods 33:436-445. https://doi .org/10.1016/j.jff.2017.04.010.

Albenzio, M., A. Santillo, M. Caroprese, D. Ruggieri, F. Napolitano, and A. Sevi. 2013. Physicochemical properties of Scamorza ewe milk cheese manufactured with different probiotic cultures. J. Dairy Sci. 96:2781-2791. https://doi.org/10.3168/jds.2012-6218.

Alvim, L. B., S. H. C. Sandes, B. C. Silva, R. S. Steinberg, M. H. A. Campos, L. B. Acurcio, R. M. Arantes, J. R. Nicoli, E. Neumann, and Á. C. Nunes. 2016. Weissella paramesenteroides WpK4 reduces gene expression of intestinal cytokines, and hepatic and splenic injuries in a murine model of typhoid fever. Benef. Microbes 7:61-73. https://doi.org/10.3920/BM2015.0093.

Anderson, M. J. 2001. A new method for non-parametric multivariate analysis of variance. Austral Ecol. 26:32-46.

Asahara, T., K. Shimizu, T. Takada, S. Kado, N. Yuki, M. Morotomi, R. Tanaka, and K. Nomoto. 2011. Protective effect of Lactobacillus casei strain Shirota against lethal infection with multi-drug resistant Salmonella enterica serovar Typhimurium DT104 in mice. J. Appl. Microbiol. 110:163-173. https://doi.org/10.1111/j.1365 $-2672.2010 .04884 . x$.

Barthel, M., S. Hapfelmeier, L. Quintanilla-Martínez, M. Kremer, M. Rohde, M. Hogardt, K. Pfeffer, H. Rüssmann, and W. D. Hardt. 2003. Pretreatment of mice with streptomycin provides a Salmonella enterica serovar Typhimurium colitis model that allows analysis of both pathogen and host. Infect. Immun. 71:2839-2858. https://doi.org/10.1128/IAI.71.5.2839-2858.2003.

Bolyen, E., J. R. Rideout, M. R. Dillon, N. A. Bokulich, C. Abnet, G. A. Al-Ghalith, H. Alexander, E. J. Alm, M. Arumugam, F. Asnicar, Y. Bai, J. E. Bisanz, K. Bittinger, A. Brejnrod, C. J. Brislawn, C T. Brown, B. J. Callahan, A. M. Caraballo-Rodríguez, J. Chase, E. Cope, R. Da Silva, P. C. Dorrestein, G. M. Douglas, D. M. Durall, C. Duvallet, C. F. Edwardson, M. Ernst, M. Estaki, J. Fouquier, J. M. Gauglitz, D. L. Gibson, A. Gonzalez, K. Gorlick, J. Guo, B. Hillmann, S. Holmes, H. Holste, C. Huttenhower, G. Huttley, S. Janssen, A. K. Jarmusch, L. Jiang, B. Kaehler, K. B. Kang, C. R. Keefe, P. Keim, S. T. Kelley, D. Knights, I. Koester, T. Kosciolek, J. Kreps, M. G. I. Langille, J. Lee, R. Ley, Y-X. Liu, E. Loftfield, C. Lozupone, M. Maher, C. Marotz, B. D. Martin, D. McDonald, L. J. McIver, A. V. Melnik, J. L. Metcalf, S. C. Morgan, J. Morton, A. T. Naimey, J. A. Navas-Molina, L. F. Nothias, S. B. Orchanian, T. Pearson, S. L. Peoples, D. Petras, M. L. Preuss, E. Pruesse, L. B. Rasmussen, A. Rivers, M. S. Robeson, P. Rosenthal, N. Segata, M. Shaffer, A. Shiffer, R. Sinha, S. J. Song, J. R. Spear, A. D. Swafford, L. R. Thompson, P. J. Torres, P. Trinh, A. Tripathi, P. J. Turnbaugh, S. Ul-Hasan, J. J. J. van der Hooft, F. Vargas, Y. Vázquez-Baeza, E. Vogtmann, M. von Hippel, W. Walters, Y. Wan, M. Wang, J. Warren, K. C. Weber, C. H. D. Williamson, A. D. Willis, Z. Z. Xu, J. R. Zaneveld, Y. Zhang, Q. Zhu, R. Knight, and J. G. Caporaso. 2019. QIIME 2: Reproducible, interactive, scalable, and extensible microbiome data science. Nature Biotechnology 37:852-857. https://doi.org/10.1038/ s41587-019-0209-9.

Brink, L. R., K. Matazel, B. D. Piccolo, A. K. Bowlin, S. V. Chintapalli, K. Shankar, and L. Yeruva. 2019. Neonatal diet impacts bioregional microbiota composition in piglets fed human breast milk or infant formula. J. Nutr. 149:2236-2246. https://doi.org/ $10.1093 / \mathrm{jn} / \mathrm{nxz} 170$.

Caporaso, J. G., C. L. Lauber, W. A. Walters, D. Berg-Lyons, C. A. Lozupone, P. J. Turnbaugh, N. Fierer, and R. Knight. 2011.
Global patterns of $16 \mathrm{~S}$ rRNA diversity at a depth of millions of sequences per sample. Proc. Natl. Acad. Sci. USA 108(Supplement 1):4516-4522. https://doi.org/10.1073/pnas.1000080107.

Castillo, N. A., A. M. de Moreno de LeBlanc, C. M. Galdeano, and G. Perdigón. 2012. Probiotics: An alternative strategy for combating salmonellosis: Immune mechanisms involved. Food Res. Int 45:831-841. https://doi.org/10.1016/j.foodres.2011.04.031.

Castillo, N. A., A. M. de Moreno de LeBlanc, C. M. Galdeano, and G. Perdigón. 2013. Comparative study of the protective capacity against Salmonella infection between probiotic and nonprobiotic lactobacilli. J. Appl. Microbiol. 114:861-876. https://doi.org/10 $.1111 / \mathrm{jam} .12074$.

Chen, H.-M., Y. Wang, L.-H. Su, and C.-H. Chiu. 2013. Nontyphoid Salmonella infection: Microbiology, clinical features, and antimicrobial therapy. Pediatr. Neonatol. 54:147-152. https://doi.org/10 .1016/j.pedneo.2013.01.010.

Cichosz, G., M. Aljewicz, and B. Nalepa. 2014. Viability of the Lactobacillus rhamnosus HN001 probiotic strain in Swiss- and Dutchtype cheese and cheese-like products. J. Food Sci. 79:M1181M1188. https://doi.org/10.1111/1750-3841.12458.

Dantas, A. B., V. F. Jesus, R. Silva, C. N. Almada, E. A. Esmerino, L. P. Cappato, M. C. Silva, R. S. L. Raices, R. N. Cavalcanti, C C. Carvalho, A. S. Sant'Ana, H. M. A. Bolini, M. Q. Freitas, and A. G. Cruz. 2016. Manufacture of probiotic Minas Frescal cheese with Lactobacillus casei Zhang. J. Dairy Sci. 99:18-30. https://doi .org/10.3168/jds.2015-9880.

Das, J. K., D. Mishra, P. Ray, P. Tripathy, T. K. Beuria, N. Singh, and M. Suar. 2013. In vitro evaluation of anti-infective activity of a Lactobacillus plantarum strain against Salmonella enterica serovar Enteritidis. Gut Pathog. 5:11. https://doi.org/10.1186/1757 $-4749-5-11$.

de Moreno de LeBlanc, A., and G. Perdigón. 2010. The application of probiotic fermented milks in cancer and intestinal inflammation. Proc. Nutr. Soc. 69:421-428. https://doi.org/10.1017/ S002966511000159X.

dos Santos, K. M. O., M. A. D. Bomfim, A. D. S. Vieira, S. D. Benevides, S. M. I. Saad, F. C. A. Buriti, and A. S. Egito. 2012. Probiotic caprine Coalho cheese naturally enriched in conjugated linoleic acid as a vehicle for Lactobacillus acidophilus and beneficial fatty acids. Int. Dairy J. 24:107-112. https://doi.org/10.1016/j.idairyj .2011.12.001.

dos Santos, K. M. O., A. D. S. Vieira, F. C. A. Buriti, J. C. F. do Nascimento, M. E. S. de Melo, L. M. Bruno, M. de Fátima Borges, C. R. C. Rocha, A. C. de Souza Lopes, B. D. G. de Melo Franco, and S. D. Todorov. 2015. Artisanal Coalho cheeses as source of beneficial Lactobacillus plantarum and Lactobacillus rhamnosus strains. Dairy Sci. Technol. 95:209-230. https://doi.org/10.1007/ s13594-014-0201-6.

Edgar, R. C., B. J. Haas, J. C. Clemente, C. Quince, and R. Knight. 2011. UCHIME improves sensitivity and speed of chimera detection. Bioinformatics 27:2194-2200. https://doi.org/10.1093/ bioinformatics/btr381.

Esterbauer, H., and K. H. Cheeseman. 1990. Determination of aldehydic lipid peroxidation products: Malonaldehyde and 4-hydroxynonenal. Methods Enzymol. 186:407-421. https://doi.org/10.1016/ 0076-6879(90)86134-H.

Finlay, B. B., and J. H. Brumell. 2000. Salmonella interactions with host cells: In vitro to in vivo. Philos. Trans. R. Soc. Lond. B. Biol. Sci. 355:623-631. https://doi.org/10.1098/rstb.2000.0603.

Foley, S. L., T. J. Johnson, S. C. Ricke, R. Nayak, and J. Danzeisen. 2013. Salmonella pathogenicity and host adaptation in chickenassociated serovars. Microbiol. Mol. Biol. Rev. 77:582-607. https:/ /doi.org/10.1128/MMBR.00015-13.

Hammam, A. R. A., and M. S. I. Ahmed. 2019. Technological aspects, health benefits, and sensory properties of probiotic cheese. SN Appl. Sci. 1:1113. https://doi.org/10.1007/s42452-019-1154-4.

Haraga, A., M. B. Ohlson, and S. I. Miller. 2008. Salmonellae interplay with host cells. Nat. Rev. Microbiol. 6:53-66. https://doi.org/10 $.1038 /$ nrmicro 1788 .

Hill, C., F. Guarner, G. Reid, G. R. Gibson, D. J. Merenstein, B. Pot, L. Morelli, R. B. Canani, H. J. Flint, S. Salminen, P. C. Calder, 
and M. E. Sanders. 2014. The International Scientific Association for Probiotics and Prebiotics consensus statement on the scope and appropriate use of the term probiotic. Nat. Ver. Gastroenterol. Hepatol. 11:506-514. https://doi.org/10.1038/nrgastro.2014.66.

Jenq, R. R., Y. Taur, S. M. Devlin, D. M. Ponce, J. D. Goldberg, K. F. Ahr, E. R. Littmann, L. Ling, A. C. Gobourne, L. C. Miller, M. D. Docampo, J. U. Peled, N. Arpaia, J. R. Cross, T. K. Peets, M. A. Lumish, Y. Shono, J. A. Dudakov, H. Poeck, A. M. Hanash, J. N. Barker, M. A. Perales, S. A. Giralt, E. G. Pamer, and M. R. van den Brink. 2015. Intestinal Blautia is associated with reduced death from graft-versus-host disease. Biol. Blood Marrow Transplant. 21:1373-1383. https://doi.org/10.1016/j.bbmt.2015.04.016.

Kim, J.-H., K. Kim, and W. Kim. 2019. Cream cheese-derived Lactococcus chungangensis CAU 28 modulates the gut microbiota and alleviates atopic dermatitis in BALB/c mice. Sci. Rep. 9:446.

Kamdar, K., S. Khakpour, J. Chen, V. Leone, J. Brulc, T. Mangatu, D. A. Antonopoulos, E. B. Chang, S. A. Kahn, B. S. Kirschner, G. Young, and R. W. DePaolo. 2016. Genetic and metabolic signals during acute enteric bacterial infection alter the microbiota and drive progression to chronic inflammatory disease. Cell Host Microbe 19:21-31. https://doi.org/10.1016/j.chom.2015.12.006.

Katoh, K., K. Misawa, K. Kuma, and T. Miyata. 2002. MAFFT: A novel method for rapid multiple sequence alignment based on fast Fourier transform. Nucleic Acids Res. 30:3059-3066. https://doi .org/10.1093/nar/gkf436.

Kemgang, T. S., S. Kapila, V. P. Shanmugam, S. Reddi, and R. Kapila. 2016. Fermented milk with probiotic Lactobacillus rhamnosus S1K3 (MTCC5957) protects mice from salmonella by enhancing immune and nonimmune protection mechanisms at intestinal mucosal level. J. Nutr. Biochem. 30:62-73. https://doi.org/10.1016/j .jnutbio.2015.11.018.

Korpela, K., A. Salonen, L. J. Virta, M. Kumpu, R. A. Kekkonen, and W. M. de Vos. 2016. Lactobacillus rhamnosus $G G$ intake modifies preschool children's intestinal microbiota, alleviates penicillin-associated changes, and reduces antibiotic use. PLoS One 11:e0154012. https://doi.org/10.1371/journal.pone.0154012.

Krawisz, J. E., P. Sharon, and W. F. Stenson. 1984. Quantitative assay for acute intestinal inflammation based on myeloperoxidase activity. Assessment of inflammation in rat and hamster models. Gastroenterology 87:1344-1350. https://doi.org/10.1016/0016 $-5085(84) 90202-6$.

Lozupone, C., and R. Knight. 2005. UniFrac: A new phylogenetic method for comparing microbial communities. Appl. Environ. Microbiol. 71:8228-8235. https://doi.org/10.1128/AEM.71.12.8228 -8235.2005 .

Luu, T. H., C. Michel, J. M. Bard, F. Dravet, H. Nazih, and C. BobinDubigeon. 2017. Intestinal proportion of Blautia sp. is associated with clinical stage and histoprognostic grade in patients with early-stage breast cancer. Nutr. Cancer 69:267-275. https://doi.org/ 10.1080/01635581.2017.1263750.

Ma, T., Y. Suzuki, and L. L. Guan. 2018. Dissect the mode of action of probiotics in affecting host-microbial interactions and immunity in food producing animals. Vet. Immunol. Immunopathol. 205:35-48. https://doi.org/10.1016/j.vetimm.2018.10.004.

Marco, M. L., D. Heeney, S. Binda, C. J. Cifelli, P. D. Cotter, B. Foligné, M. Gänzle, R. Kort, G. Pasin, A. Pihlanto, E. J. Smid, and R. Hutkins. 2017. Health benefits of fermented foods: Microbiota and beyond. Curr. Opin. Biotechnol. 44:94-102. https://doi.org/ 10.1016/j.copbio.2016.11.010.

Marianelli, C., N. Cifani, and P. Pasquali. 2010. Evaluation of antimicrobial activity of probiotic bacteria against Salmonella enterica ssp. enterica serovar Typhimurium 1344 in a common medium under different environmental conditions. Res. Microbiol. 161:673680. https://doi.org/10.1016/j.resmic.2010.06.007.

McMurdie, P. J., and S. Holmes. 2013. phyloseq: An R package for reproducible interactive analysis and graphics of microbiome census data. PLoS One 8:e61217. https://doi.org/10.1371/journal.pone .0061217 .

Million, M., M. T. Alou, S. Khelaifia, D. Bachar, J.-C. Lagier, N. Dione, S. Brah, P. Hugon, V. Lombard, F. Armougom, J. Fromonot, C. Robert, C. Michelle, A. Diallo, A. Fabre, R. Guieu, C. Sokhna,
B. Henrissat, P. Parola, and D. Raoult. 2016. Increased gut redox and depletion of anaerobic and methanogenic prokaryotes in severe acute malnutrition. Sci. Rep. 6:26051. https://doi.org/10 $.1038 / \operatorname{srep} 26051$.

Moreau, M. R., D. S. S. Wijetunge, M. L. Bailey, S. R. Gongati, L. L. Goodfield, E. M. K. K. Hewage, M. J. Kennett, C. Fedorchuk, Y. V. Ivanov, J. E. Linder, B. M. Jayarao, and S. Kariyawasam. 2016. Growth in egg yolk enhances Salmonella Enteritidis colonization and virulence in a mouse model of human colitis. PLoS One 11:e0150258. https://doi.org/10.1371/journal.pone.0150258.

Mushtaq, M., A. Gani, F. A. Masoodi, and M. Ahmad. 2016. Himalayan cheese (Kalari/Kradi) and effect of different probiotic strains on oxidative stability, microbiological, sensory and nutraceutical properties during storage. LWT Food Sci Technol. 67:74-81. https: //doi.org/10.1016/j.lwt.2015.11.039.

Noto Llana, M., S. H. Sarnacki, M. D. R. Aya Castañeda, M. I. Bernal, M. N. Giacomodonato, and M. C. Cerquetti. 2013. Consumption of Lactobacillus casei fermented milk prevents Salmonella reactive arthritis by modulating IL-23/IL-17 expression. PLoS One 8:e82588. https://doi.org/10.1371/journal.pone.0082588.

Oliveira, M. E. G., E. F. Garcia, R. C. R. E. Queiroga, and E. L. de Souza. 2012. Technological, physicochemical and sensory characteristics of a Brazilian semi-hard goat cheese (coalho) with added probiotic lactic acid bacteria. Sci. Agric. 69:370-379. https://doi .org/10.1590/S0103-90162012000600005.

Petrullo, L., M. J. Jorgensen, N. Snyder-Mackler, and A. Lu. 2019. Composition and stability of the vervet monkey milk microbiome. Am. J. Primatol. 81:e22982. https://doi.org/10.1002/ajp.22982.

Price, M. N., P. S. Dehal, and A. P. Arkin. 2010. FastTree 2-Approximately maximum-likelihood trees for large alignments. PLoS One 5:e9490. https://doi.org/10.1371/journal.pone.0009490.

Quast, C., E. Pruesse, P. Yilmaz, J. Gerken, T. Schweer, P. Yarza, J. Peplies, and F. O. Glöckner. 2013. The SILVA ribosomal RNA gene database project: Improved data processing and web-based tools. Nucleic Acids Res. 41:D590-D596. https://doi.org/10.1093/ nar/gks1219.

Reeves, A. E., M. J. Koenigsknecht, I. L. Bergin, and V. B. Young. 2012. Suppression of Clostridium difficile in the gastrointestinal tracts of germfree mice inoculated with a murine isolate from the family Lachnospiraceae. Infect. Immun. 80:3786-3794. https://doi .org/10.1128/IAI.00647-12.

Rodrigues, R., G. Guerra, J. Soares, K. Santos, F. Rolim, P. Assis, D. Araújo, R. F. Araújo, V. B. Garcia, A. A. de Araújo, and R. Queiroga. 2018. Lactobacillus rhamnosus EM1107 in goat milk matrix modulates intestinal inflammation involving NF- $\mathrm{B}$ p65 and SOCs-1 in an acid-induced colitis model. J. Funct. Foods 50:78-92. https://doi.org/10.1016/j.jff.2018.09.013.

Rognes, T., T. Flouri, B. Nichols, C. Quince, and F. Mahé. 2016. VSEARCH: A versatile open source tool for metagenomics. PeerJ 4:e2584. https://doi.org/10.7717/peerj.2584.

Rolim, F. R. L., K. M. O. dos Santos, S. C. de Barcelos, A. S. do Egito, T. S. Ribeiro, M. L. Conceição, M. Magnani, M. E. G. de Oliveira, and R. C. R. E. Queiroga. 2015. Survival of Lactobacillus rhamnosus EM1107 in simulated gastrointestinal conditions and its inhibitory effect against pathogenic bacteria in semi-hard goat cheese. LWT Food Sci Technol. 63:807-813. https://doi.org/10 .1016/j.lwt.2015.05.004.

Santos, R. L., M. Raffatellu, C. L. Bevins, L. G. Adams, C. Tukel, R. M. Tsolis, and A. J. Baumler. 2009. Life in the inflamed intestine, Salmonella style. Trends Microbiol. 17:498-506. https://doi.org/ 10.1016/j.tim.2009.08.008.

Segata, N., J. Izard, L. Waldron, D. Gevers, L. Miropolsky, W. S. Garrett, and C. Huttenhower. 2011. Metagenomic biomarker discovery and explanation. Genome Biol. 12:R60. https://doi.org/10.1186/ gb-2011-12-6-r60.

Sha, Y., M. Liu, B. Wang, K. Jiang, C. Qi, and L. Wang. 2016. Bacterial population in intestines of Litopenaeus vannamei fed different probiotics or probiotic supernatant. J. Microbiol. Biotechnol. 26:1736-1745. https://doi.org/10.4014/jmb.1603.03078.

Silva, C. A., C. J. Blondel, C. P. Quezada, S. Porwollik, H. L. Andrews-Polymenis, C. S. Toro, M. Zaldívar, I. Contreras, M. Mc- 
Clelland, and C. A. Santiviago. 2012. Infection of mice by Salmonella enterica serovar Enteritidis involves additional genes that are absent in the genome of serovar Typhimurium. Infect. Immun. 80:839-849. https://doi.org/10.1128/IAI.05497-11.

Slačanac, V., R. Božanić, J. Hardi, J. R. Szabó, M. Lučan, and V. Krstanović. 2010. Nutritional and therapeutic value of fermented caprine milk. Int. J. Dairy Technol. 63:171-189. https://doi.org/ 10.1111/j.1471-0307.2010.00575.x.

Suchodolski, J. S. 2013. Gastrointestinal microbiota. Canine and feline. Gastroenterology 2:32-41.

Tennant, S. M., E. L. Hartland, T. Phumoonna, D. Lyras, J. I. Rood, R. N. Robins-Browne, and I. R. Van Driel. 2008. Influence of gastric acid on susceptibility to infection with ingested bacterial pathogens. Infect. Immun. 76:639-645. https://doi.org/10.1128/ IAI.01138-07.

Thiennimitr, P., S. E. Winter, M. G. Winter, M. N. Xavier, V. Tolstikov, D. L. Huseby, T. Sterzenbach, R. M. Tsolis, J. R. Roth, and A. J. Bäumler. 2011. Intestinal inflammation allows Salmonella to use ethanolamine to compete with the microbiota. Proc. Natl. Acad. Sci. USA 108:17480-17485. https://doi.org/10.1073/pnas .1107857108

Verruck, S., A. Dantas, and E. S. Prudencio. 2019. Functionality of the components from goat's milk, recent advances for functional dairy products development and its implications on human health.
J. Funct. Foods 52:243-257. https://doi.org/10.1016/j.jff.2018.11 .017 .

Wang, Y., J. Sun, H. Zhong, N. Li, H. Xu, Q. Zhu, and Y. Liu. 2017. Effect of probiotics on the meat flavour and gut microbiota of chicken. Sci. Rep. 7:6400. https://doi.org/10.1038/s41598-017 $-06677-z$.

Weinberg, J. D., M. Haschke, K. Kutz, J. Thebault, and A. Stevenson. 2018. Phase I randomized controlled study of a single-strain live biotherapeutic (Blautia hydrogenotrophica) in the treatment of patients with irritable bowel syndrome (IBS): Effects on the microbiome. Gastroenterology 154:S852-S853. https://doi.org/10 .1016/S0016-5085(18)32886-5.

Zhang, W., Y. H. Zhu, D. Zhou, Q. Wu, D. Song, J. Dicksved, and J. F. Wang. 2017. Oral administration of a select mixture of Bacillus probiotics affects the gut microbiota and goblet cell function following Escherichia coli challenge in newly weaned pigs of genotype MUC4 that are supposed to be enterotoxigenic E. coli F4ab/ac receptor negative. Appl. Environ. Microbiol. 83:e02747-16. https:/ /doi.org/10.1128/AEM.02747-16.

Zhang, Z., J. Lv, L. Pan, and Y. Zhang. 2018. Roles and applications of probiotic Lactobacillus strains. Appl. Microbiol. Biotechnol. 102:8135-8143. https://doi.org/10.1007/s00253-018-9217-9. 